\title{
Sonata para piano n. 1 de Francisco Mignone: uma comparação de performances
}

\author{
Sonata for piano n. 1 by Francisco Mignone: \\ a performance comparison
}

\author{
Nayane Nogueira Soares* \\ Universidade Federal do Rio Grande do Sul, Brasil \\ nayanenogueira@msn.com \\ Cristina Capparelli Gerling** \\ Universidade Federal do Rio Grande do Sul, Brasil \\ ccgerling@gmail.com
}

*Doutoranda e Mestra em Música, subárea de Práticas Interpretativas/Piano, pela Universidade Federal do Rio Grande do Sul e Bacharel em Música - Instrumento/Piano pela Universidade Federal de Uberlândia (2015).

**Universidade Federal do Rio Grande do Sul; CNPq-Conselho Nacional para o Desenvolvimento Científico e Tecnológico. Doutora em Música pela Boston University; Mestre em Música pelo New England Conservatory; Estágios pós-doutorais realizados nas Universidades de lowa e Connecticut; "Indiana Chair" da Indiana University, Bloomington (2014).

Submetido em 08/10/2018, Aprovado em 20/11/2018 


\section{Resumo}

Este texto apresenta um recorte de uma investigação sobre as decisões interpretativas relacionadas ao timing, dinâmica e articulação de quatro execuções do primeiro movimento da Sonata para piano n.1 de Francisco Mignone. Por meio da comparação de gravações, foram identificadas estratégias expressivas adotadas pelos intérpretes profissionalmente reconhecidos por seu nível de expertise. No processo de comparação torna-se evidente como o direcionamento expressivo do discurso musical em determinados trechos da obra é determinado por manipulações coordenadas de timing e dinâmica.

Palavras-chave: análise de gravações; análise rítmica; expressividade; timing e dinâmica; Sonata para piano n.1 de Francisco Mignone.

\section{Abstract}

This paper investigates some of the interpretive decisions related to the timing, dynamics and articulation of four renditions of the first movement of Piano Sonata $n .1$ by Francisco Mignone. Through the comparison of recordings expressive strategies adopted by performers widely recognized for their level of expertise have been identified. In the process of comparison it has become evident how the expressive direction of the musical discourse as well as the different sections of the piece result from the coordinated manipulations of timing and dynamics.

Keywords: analyses of recordings; rhythmic analysis; timing and dynamic; expressivity profiling; Sonata $\mathrm{n} .1$ for piano by Francisco Mignone. 


\section{Introdução}

As temáticas de pesquisas sobre performance propriamente dita estão utilizando cada vez mais as ferramentas tecnológicas ${ }^{1}$ para compreender e sistematizar processos interpretativos musicais. Graças aos avanços da tecnologia e ao interesse teórico dos campos relacionados à psicoacústica, biomecânica, inteligência artificial e seus reflexos na música, tornaram-se possíveis o desenvolvimento e aprimoramento de inúmeras ferramentas computacionais que viabilizaram a realização de pesquisas de arquivos sonoros. As gravações realizadas desde o início do século XX constituem um amplo campo de experimentação para pesquisas relacionadas às habilidades motoras, cognitivas e sobretudo artísticas. Para Clarke (1999, p. 62), a performance musical é vista como uma forma concreta de pensamento musical, na qual o intérprete pode expressar suas concepções musicais através das realizações físicas do que é notado na partitura e por manipulações intencionais ${ }^{2}$ em relação às indicações escritas. O autor afirma que o objetivo do intérprete é "aproximar-se o mais possível da total transparência entre concepção e ação, de tal modo que qualquer aspecto da sua compreensão musical encontre expressão na própria performance" (CLARKE, 1999, p. 62). Para Sloboda (1982, p. 480), "sempre que alguém executa uma música, ele ou ela está traduzindo uma representação mental ou [expondo] um plano da música em ação".

Podemos afirmar que os registros fonográficos, nos mais variados formatos, são utilizados como fonte de consulta para instrumentistas dos mais diversos níveis e, muitas vezes, elucidam questões interpretativas. Portanto, não causa estranhamento que, o que já vinha sendo praticado rotineiramente, tenha se transformado em relevante ferramenta analítica no estudo científico e acadêmico da música instrumental e vocal. A partir dos anos 2000, com a contribuição das pesquisas realizadas pelo Centre for the History and Analysis of Recorded Music (CHARM), o estudo sistemático da performance, especialmente o estudo de gravações, foi incorporado aos estudos musicológicos como uma modalidade de análise. Com isso, esse tipo de estudo passou a integrar uma nova vertente da musicologia, denominada musicologia empírica. Segundo Cook e Clarke (2004, p. 5), essa vertente musicológica pode ser pensada como "a musicologia que incorpora uma consciência fundamentada tanto no potencial para trabalhar com uma quantidade relevante de dados, quanto à apropriação de métodos para alcançar este objetivo".

Este trabalho propõe uma análise de quatro performances segundo as normas da modalidade análise de performance através da comparação de gravações. Assim, o objetivo deste trabalho é investigar empiricamente as possibilidades e decisões interpreses e métodos de inteligência artificial: modelos estatísticos (REPP, 1990, 1992a), matemáticos (TODD, 1989, 1992, 1995) e multidimensionais (REPP, 1992, 1999). Dentre as ferramentas tecnológicas incluem os softwares tais como o Sonic Visualiser para extração de dados quantitativos de uma execução musical, bem como a compreensão de diversos aspectos sonoros e expressivos de uma performance.

2 Manipulações ou inflexões expressivas são os elementos da performance musical que um instrumentista manipula durante a execução para conferir identidade própria. São as decisões interpretativas relacionadas ao timing (agógica), dinâmicas, articulações, pedalização, dentre outras estratégias usadas em uma performance.
} 
tativas quanto ao timing, dinâmica e articulação por meio da comparação de gravações, a fim de identificar aspectos expressivos que delineiam o discurso musical do primeiro movimento da Sonata para piano n.1 de Francisco Mignone composta em $1941^{3}$. A análise de gravações voltou-se para investigação das estratégias expressivas adotadas pelos intérpretes selecionados para evidenciar o direcionamento temporal dos eventos tanto no conjunto global da obra quanto em determinados trechos. Os registros fonográficos da Sonata não são numerosos. As gravações escolhidas ${ }^{4}$ são de intérpretes brasileiros gravadas em estúdio ou ao vivo e, estão disponibilizadas comercialmente por mídia social (YouTube) e CD.

\title{
Sonata para piano n.1 de Francisco Mignone
}

De acordo com o Catálogo de Obras de Francisco Mignone (2016), suas primeiras experiências com esta forma musical data dos anos de 1916 e 1919 quando compôs duas sonatas para violino e piano ou órgão. No decorrer de sua vida, produziu uma variedade de obras com o título sonata para diversas formações instrumentais tais como, piano e violino, piano e violoncelo, piano e viola, fagote solo, sopros e piano, flauta e oboé, sonatas para trios de sopros, bem como quatro sonatas para piano solo.

Com base em uma avaliação do repertório latino-americano para piano no século XX, Gerling (2016, p. 2) ressalta as sonatas dodecafônicas de Cláudio Santoro bem como duas obras neoclássicas de grande porte com data anterior a 1950: a Sonata n. 1 de Francisco Mignone de 1941 e a Sonata Breve de Lorenzo Fernandez de 1948. Autores como Martins (1990), Geirlaugsdóttir (1997) e Verhaalen (1971) adotaram a Sonata n. 1 de Mignone como objeto de estudo em seus trabalhos e assinalam, por exemplo, as recorrentes mudanças nas configurações rítmicas como um aspecto importante na obra.

Sobre aspectos gerais da Sonata, Martins (1990) comenta que Mignone utiliza um amplo "quadro técnico-pianístico" e complementa dizendo que:

\begin{abstract}
A Sonata $n .1$ de Mignone pode ser considerada como substancial detectação de seu código tecladístico característico: linhas arpejadas "fixas" e contínuas, notas repetidas, ostinatos (primeiro movimento), buscas timbrística (segundo movimento), paralelismo "assimétricos" (terceiro movimento), mãos alternadas (primeiro e terceiro movimentos), deslocamento métrico em secções definidas (MARTINS, 1990, p. 95).
\end{abstract}

Pelo excerto acima, Martins (1990) apresenta uma lista substancial de elementos utilizados pelo compositor. Em especial, ostinatos, notas repetidas e figuras arpejadas constituem uma parte considerável da escrita pianística da obra. Ambos, Martins (1990) e Geirlaugsdóttir (1997), concordam, sobretudo, quanto à importância dos ostinatos e

3 Segundo afirmação de Heitor Alimonda, mencionada por Flávio Silva no Catálogo de Obras de Francisco Mignone (2016), essa obra foi a primeira sonata escrita por um compositor brasileiro para piano solo. Afirmação esta contestada por Alexandre Dias do Instituto do Piano Brasileiro e confirmada por Sonatas compostas já em 1915 tais como o opus 29 de Murilo Furtado, dentre outras obras com o mesmo título. De fato, Alberto Nepomuceno compôs uma Sonata para Piano em Sol menor em 1894.

$4 \quad$ O critério de escolha das gravações foi a qualidade sonora e disponibilidade comercial. 
notas repetidas no primeiro movimento da sonata. No entanto, Geirlaugsdóttir (1997) realça o trecho de notas repetidas do ponto de vista formal, como um segundo tema ou como ela denomina, "tema-matraca". A autora também afirma que o ritmo se mostra o melhor representante da "brasilidade" na obra tanto no material temático quanto nos ostinatos. Verhaalen (1971), assim como Geirlaugsdóttir (1997), reafirma a importância do ritmo na obra e destaca uma tendência da organização melódica em quadraturas com ênfase no intervalo de terças, bem como o frequente uso da sétima menor em melodias e ostinatos.

Dedicada à pianista e pedagoga brasileira Magdalena Tagliaferro (1893-1986), a Sonata $n .1$ de Francisco Mignone, é organizada em três movimentos: Moderato, Andantino, quasi Allegretto e Moderato. Nos seus 110 compassos, a estrutura formal do primeiro movimento é claramente delineada por desenhos rítmicos diferenciados e característicos em cada uma das suas seções. O material melódico-temático e os ostinatos, apesar de bastante diferenciados entre si quanto à figuração rítmica e padrões de articulação, são elementos constantes e recorrentes apresentados nos variados registros do instrumento. Antes de proceder à análise das quatro performances, apresentamos uma breve explicação da disposição formal e estrutural do primeiro movimento da Sonata.

Como sonata convencional, o movimento pode ser organizado em Exposição, Desenvolvimento e Recapitulação (Quadro 1).

\begin{tabular}{c|c|c|c|c|c}
\multicolumn{3}{c|}{$\begin{array}{c}\text { EXPOSIÇÃo } \\
\text { (c. 1-57) }\end{array}$} & \multicolumn{2}{c|}{$\begin{array}{c}\text { DESENVOLVIMENTO } \\
\text { (c. 58-82) }\end{array}$} & $\begin{array}{c}\text { RECAPITULAÇÃO } \\
\text { (c. 83-110) }\end{array}$ \\
\hline $\begin{array}{c}\text { Tema 1 } \\
\text { c. 1-20 }\end{array}$ & $\begin{array}{c}\text { Transição/ } \\
\text { Quebra } \\
\text { c. } 21\end{array}$ & $\begin{array}{c}\text { Tema 2 } \\
\text { c. 22-57 }\end{array}$ & c. 58-81 & $\begin{array}{c}\text { Transição/ } \\
\text { Quebra } \\
\text { c. 82 }\end{array}$ & $\begin{array}{c}\text { Tema 2 - c. 83-100 } \\
\text { Tema 1 - c. 101-110 }\end{array}$ \\
\hline
\end{tabular}

Quadro 1: Estrutura formal do primeiro movimento da Sonata.

Os eventos musicais que compõem o primeiro movimento da Sonata são organizados por dois aspectos principais: estabilidade harmônica e rítmica. Assim, a estrutura formal do movimento é delineada pelos desenhos rítmicos característicos de cada seção, bem como por uma organização tonal constituída por harmonias estáticas e longos pedais.

Nesta proposta de estruturação formal, apresento o movimento organizado em seis seções (Quadro 2). Em especial, ressalto dois aspectos relevantes: a seção D (c. 5780) corresponde ao desenvolvimento e, mais relevante para o entendimento da forma, o tema 2 (c. 81-99) precede o tema 1 (c. 100-109) na seção de recapitulação. O movimento encerra sem uma Coda, ainda que haja uma terminação (c. 106-109) constituída pela extensão do ostinato característico da seção inicial (A).

\begin{tabular}{c|c|c|c|c|c}
\multicolumn{3}{c|}{ EXPOSIÇÃO } & DESENVOLVIMENTO & \multicolumn{2}{c}{ RECAPITULAÇÃO } \\
\hline SEÇÃO A & SEÇÃO B & SEÇÃO C & SEÇÃO D & SEÇÃO B' & SEÇÃO A' \\
C. $1-20$ & C. $21-39$ & c. $40-57$ & C. $58-81$ & c. 82-100 & c. 101-110 \\
\hline
\end{tabular}


Como podemos observar nos quadros 1 e 2, o primeiro movimento da Sonata apresenta um esquema formal modificado. Assim como Bartok, Shostakovich e Barber em algumas das composições mais marcantes da primeira metade do século XX, Mignone também adota um esquema de sonata em forma de arco (arch form) demonstrando domínio da técnica composicional. A sonata com seus temas diferenciados, presta-se para este esquema formal pois é uma estrutura musical baseada na repetição em ordem inversa de seções da obra. Tais seções podem ser repetidas na íntegra ou com material temático abreviado. Na Sonata n. 1 Mignone inverte a ordem dos temas na seção de recapitulação (c. 82-110), apresentando primeiramente o tema 2 na íntegra seguido de parte do material temático do tema 1.

Na seção A (c. 1-20, figura 1), as oitavas graves do baixo (m.e.), apoiam o ostinato de notas curtas (m.d.) que vão caracterizar a apresentação do tema 1. O ostinato é formado por quartas e quintas ascendentes e descendentes. No desenho rítmico do ostinato o intérprete se depara com a primeira decisão interpretativa, em que a figuração pode ser executada de dois em dois, três em três ou ainda em seis notas consecutivas. Considerando os sinais de dinâmica (crescendo e decrescendo), é mais condizente realizar o desenho rítmico como uma unidade de seis notas consecutivas e um direcionamento dinâmico para a nota mais aguda de cada grupo. As alturas presentes na configuração da mão esquerda, as oitavas lentas e majestosas, são ecoadas na filigrana da voz superior com nuances de crescendo e decrescendo entre as frases compostas por três ou quatro compassos.
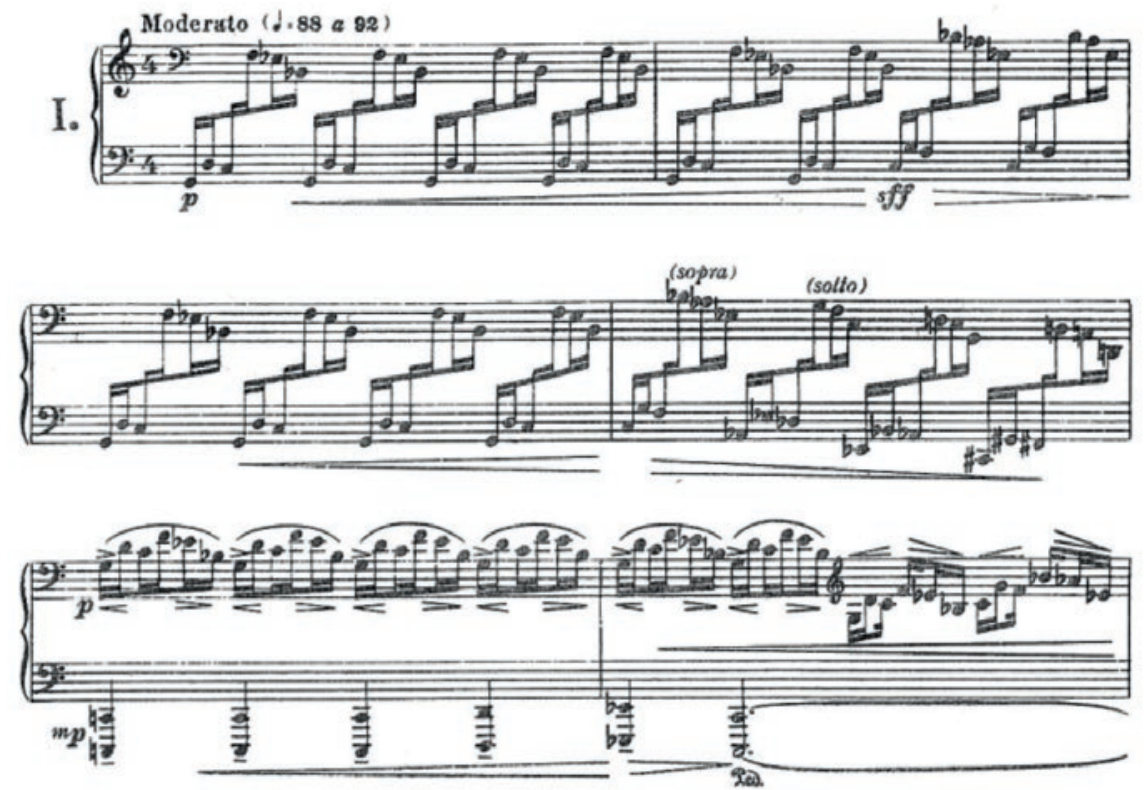

Figura 1: Seção A, c. 1-6 do primeiro movimento da Sonata.

Na passagem de transição entre as seções A e B (c. 21, figura 2) há uma quebra de desenho rítmico. Os blocos de acorde formados por segundas, quartas e quintas ascendentes interrompem bruscamente o discurso musical que até este momento se mostra homogêneo. A mudança de padrão rítmico, a mudança da métrica e a sequência 
de acordes que percorrem do registro grave ao agudo, enfatizado pela súbita dinâmica forte, interrompem o fluxo e chamam a atenção do ouvinte. Prosseguindo, nos próximos dois compassos (c. 22-23) Mignone apresenta o segundo ostinato que vai caracterizar a apresentação do segundo tema.

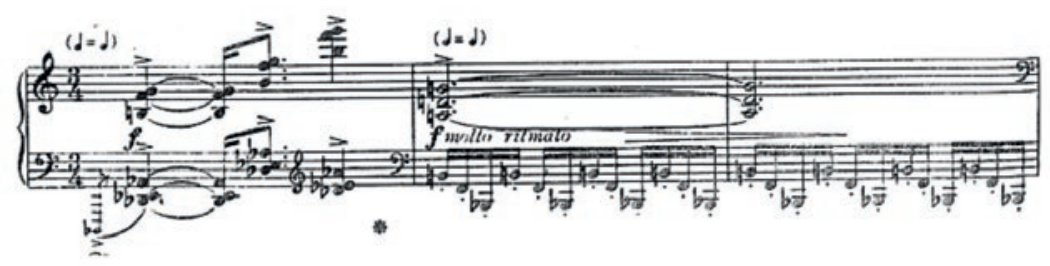

Figura 2: Quebra de desenho rítmico, c. 21-23.

Na seção B (c. 21-39, figura 3), as duas vozes (ou mãos) são constituídas por figurações com notas repetidas, a mais grave (m.e.) mantém uma figuração mais aberta com quartas e quintas descendentes em staccato e dissonante em relação ao material anterior. O material utilizado na mão esquerda foge da escala de Dó inicialmente utilizada como base do Tema 1 ao confrontar Sib e Sił (c. 22-31) e Mib e Mi ต (c. 32-39). A voz superior (m.d.) centra-se na repetição das notas Fá (c. 24-31) e Láb (c. 32-37), sucedida por dois compassos contrastantes formados por notas longas e de caráter melódico. Nesta intersecção melódica que replica partes do Tema 1, o movimento rítmico ressalta um escrita sincopada.

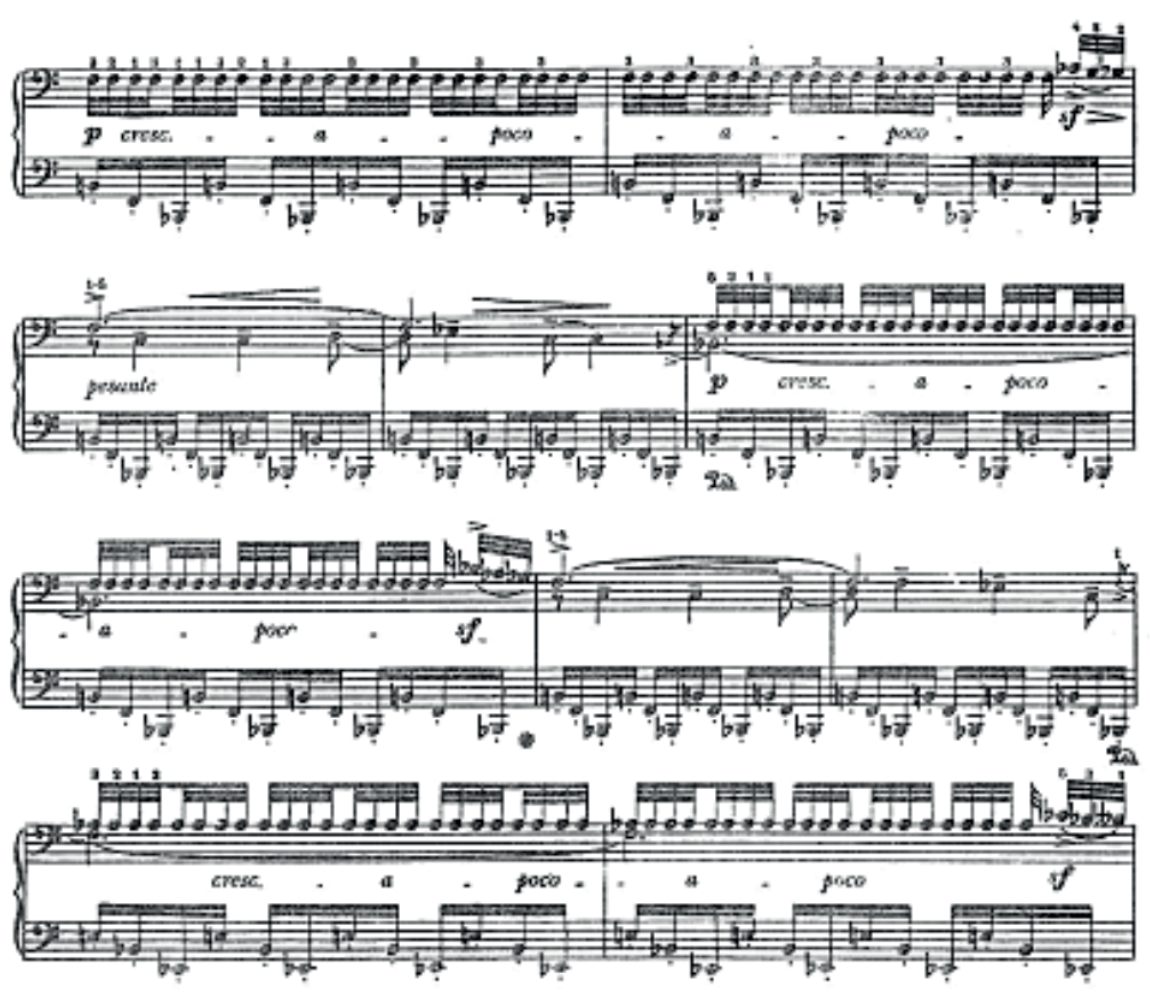

Figura 3: Seção B (c. 24-33) do primeiro movimento da Sonata. 
Na seção C (c. 40-57, figura 4), a voz do baixo mantém a figuração do ostinato da seção anterior, quartas e quintas descendentes em staccato, no entanto apresenta um movimento mais ativo e dinâmico na mão esquerda. No desenho rítmico do ostinato o intérprete se depara com mais uma decisão interpretativa, sendo que, a figuração pode ser interpretada como um grupo de quatro semicolcheias coincidindo com a métrica ou um grupo de três semicolcheias em quartas descendentes. Considerando a ideia fraseológica da figuração rítmica e tendo as notas Láb-Fá-Mi-Fá (c. 40, figura 4) como pontos estruturais da linha condutora da frase, é condizente executá-lo articulando o grupo de três notas. A mão direita apresenta novamente o tema inicial com acréscimos na textura, isto é, em figurações sincopadas e polifônicas.

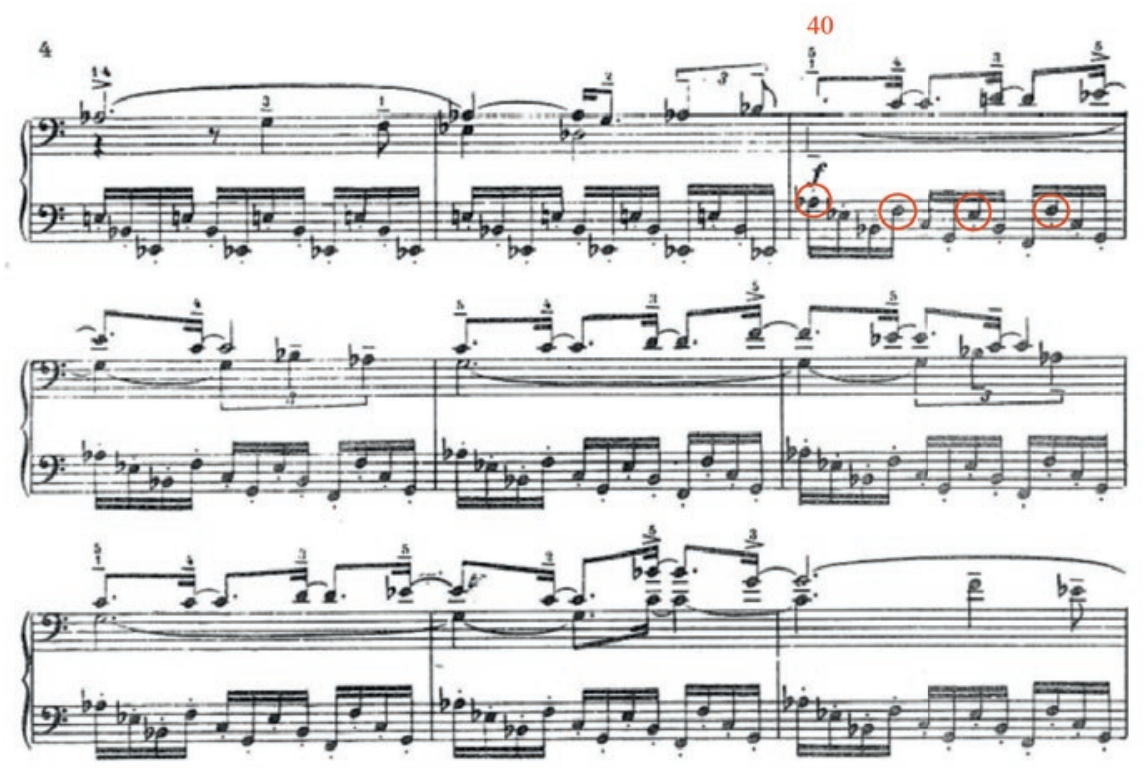

Figura 4: Trecho da Seção C (c. 38-43) do primeiro movimento da Sonata.

O encaminhamento harmônico/melódico das seções anteriores é delineado de acordo com a coleção escalar do modo Eólico e Frígio, baseado em Dó. Na seção D (c. 58-81, figura 5) há uma surpresa, Mignone apresenta uma passagem arpejada sobre Dó Maior sem preparação harmônica prévia no primeiro tempo do primeiro compasso da seção (c. 58). Essa mudança de modo menor para o modo maior (Modo Eólio e Frígio para o Modo Jônio e Mixolídio) é um aspectos que fortifica minha concepção da seção como desenvolvimento ou passagem ${ }^{5}$ do primeiro movimento da Sonata. No início da seção D, os quatro primeiros compassos (c. 57-60) assemelham-se aos quatro compassos iniciais do movimento (c. 1-4), em que a ideia é apresentar o ostinato que vai caracterizar a seção. O ostinato da seção D (m.e.) é formado por cinco tríades diatônicas ascendentes e descendentes (C, Dm, Em, F e G) e a articulação em legato contrasta vivamente com os ostinatos anteriores em staccato. Já a voz superior (m.d., c. 57-80)

5 Schenker refere-se a seção de desenvolvimento como "passagem" pois trata-se de uma passagem situada entre a exposição e a recapitulação que intermedia ou intensifica as relações tonais entre elas. Para Cogan e Escot (2013, p. 237) o termo "passagem" descreve melhor o papel tonal dessa seção que é "conduzir" e incorporar relações tonais mais distantes à orbita tonal. 
replica o tema inicial, descontadas as notas ornamentais e rápidas incidências cromáticas entre as notas reais. A seção de desenvolvimento, ou seja, a passagem entre os temas principais e recapitulados, se desenvolve nos registros médio e agudo para criar uma sonoridade delicada e ingênua.

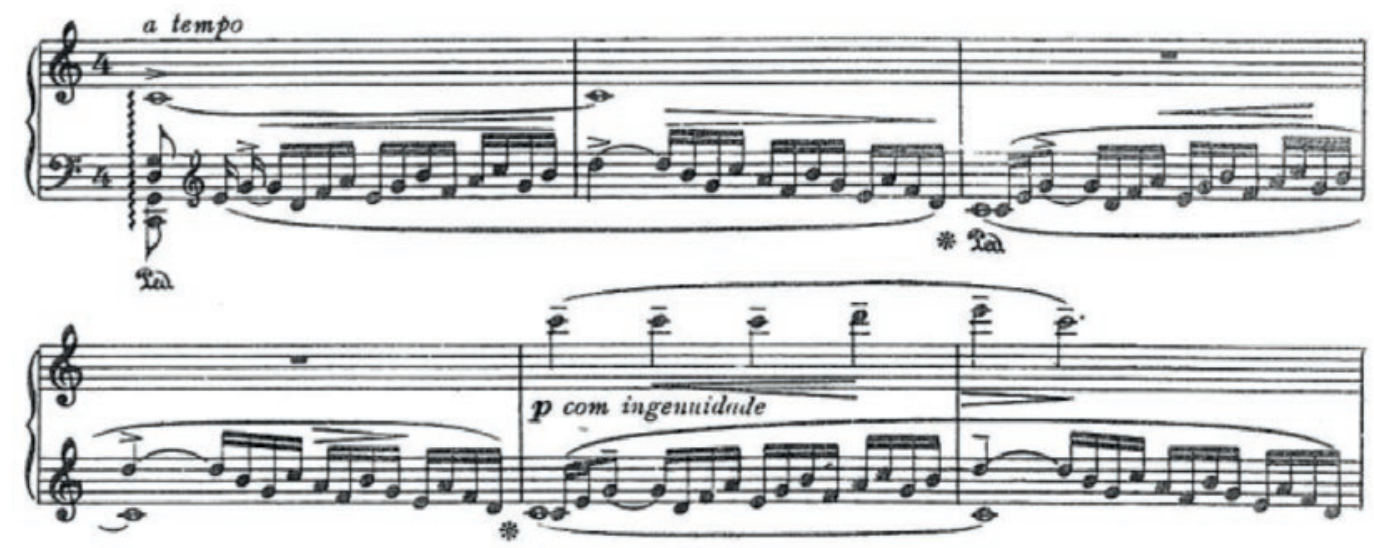

Figura 5: Trecho da Seção D (c. 58-63) do primeiro movimento da Sonata.

No compasso 82 (Figura 6), assim como no compasso 21, há novamente uma quebra de desenho rítmico que antecede a seção de recapitulação da Sonata. Esta quebra é constituída por acordes maiores, menores e diminutos com sétima em movimento descendente. Funciona como um elemento de ligação entre o final da seção $D$ no registro agudo e o início da seção B' no registro grave. Na continuação dos próximos dois compassos (c. 83-84) o compositor retoma a figuração rítmica e harmônica do tema 2, iniciando a recapitulação do movimento.

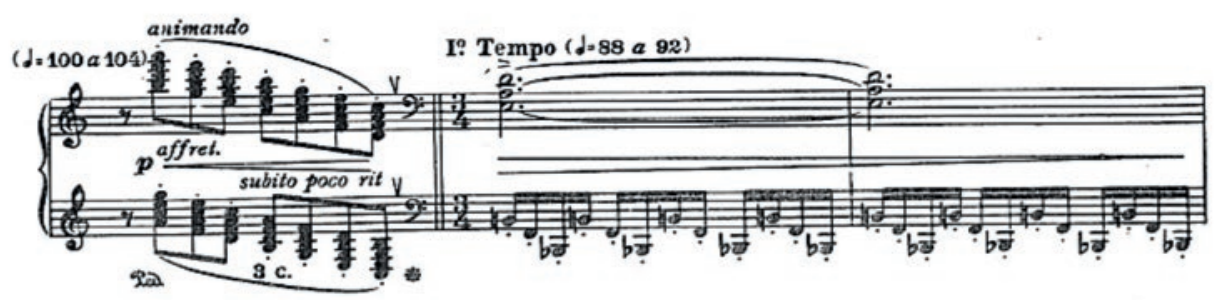

Figura 6: Quebra de desenho rítmico (c. 82-84) do primeiro movimento da Sonata.

Na recapitulação (c. 82-109, figura 7), Mignone reproduzir primeiramente os materiais identificados como tema 2, seção B' (c. 81-99), quase exatamente como na seção B (c. 21-39). A principal diferença é que a mão direita não replica os dois compassos formados por notas longas e de caráter melódico como na primeira vez (c. 26-27, 30-31). Nesta instância, o compositor apresenta uma configuração rítmica em contratempo e sincopada. Com indicação de ataques acentuados, as formações de acordes ocorrem primeiramente por três sons em posição fechada e posteriormente os três sons voltam em posição aberta, em formação de acordes quartais. 

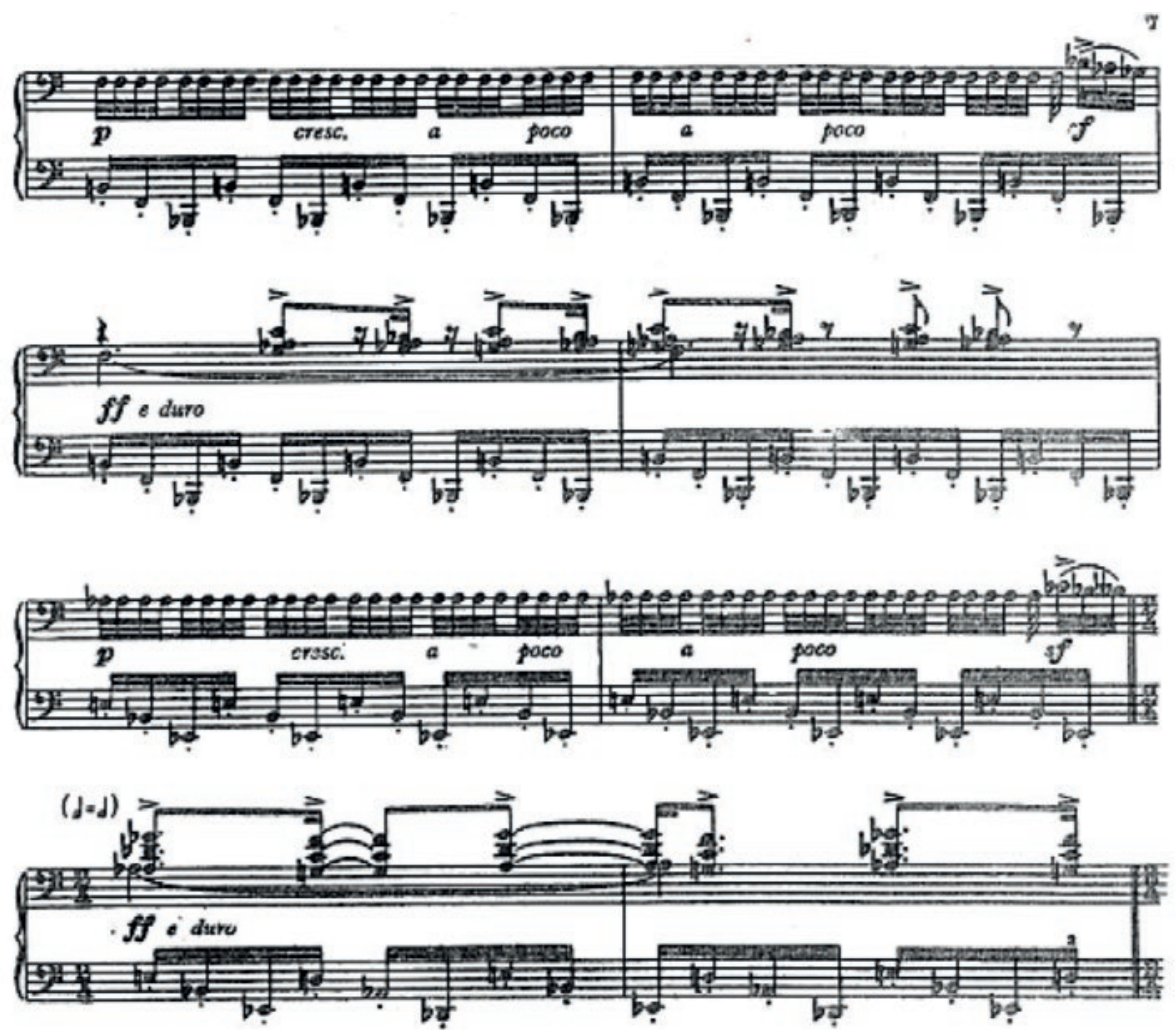

Figura 7: Trecho da Seção B' (c. 84-87) do primeiro movimento da Sonata.

Na continuação, o compositor retoma parte do material melódico (m.e.) da seção A (c. 1-20) apoiadas no ostinato de notas curtas característico da abertura do movimento (Figura 8), ou seja, como anteriormente mencionado, o tema 1 retorna de forma abreviada. Para finalizar, Mignone não apresenta uma Coda caracterizada como tal, mas prolonga o ostinato do registro agudo até o registro grave do instrumento (c. 107-109).

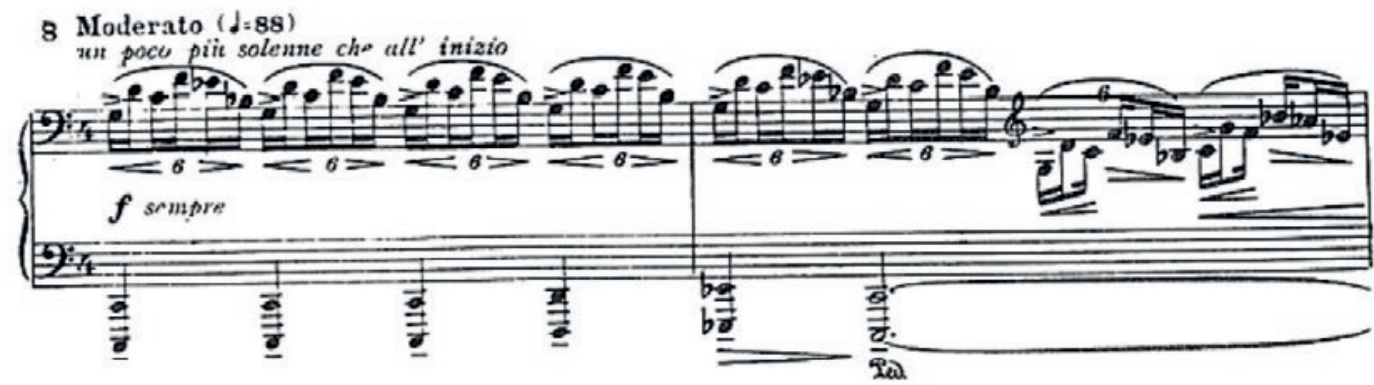

Figura 8: Trecho da seção A' (c. 101-102) do primeiro movimento da Sonata.

\section{Análise das gravações: procedimentos metodológicos}

As ferramentas computacionais, tais como os softwares ${ }^{6}$ Sonic Visualiser, Tap Snap, Expression Algorithm têm sido frequentemente utilizados como auxiliares no processo de escuta e construção interpretativa de uma obra. O software Sonic Visualiser em- 
pregado na análise de performances, sobretudo em comparações de gravações, é comumente utilizado pois proporciona diferentes formas de visualizações de arquivos de áudios, o que implica em várias opções de extração de dados. O software também apresenta uma gama de plug-ins ou módulos de extensão para fins diversos como detecção automática dos ataques das notas, estimativas de alturas e dados de intensidades. Essas configurações revelaram-se úteis no processo analítico do mapeamento do timing e das intensidades nas execuções selecionadas.

O Sonic Visualiser vem configurado com a seguinte definição: eixo vertical, intensidade do som e eixo horizontal, tempo de duração. O mapeamento do timing consiste na confecção de gráficos que mostram as inflexões do tempo no decorrer da execução da obra. Para isso, primeiramente foi marcado a pulsação de cada compasso, a fim de comparar e analisar a condução temporal entre cada batida nos trechos selecionados. O software registra visualmente essas marcações através de barras verticais e, auditivamente por meio de um som curto análogo ao metrônomo, visualizadas na camada Time Instants. Os gráficos das inflexões do tempo são gerados a partir da escolha pela opção Tempo (bpm) based on duration since previous ${ }^{7}$ item na camada Time Values. Feito esses procedimentos, o software calcula a distância entre duas marcações de tempo e gera um valor metronômico para os pontos referentes a cada marcação. A variação entre um valor e outro é expressa em curvas com perfis ascendentes que mostram a aceleração e perfis descendentes que mostram a desaceleração (Figura 9).

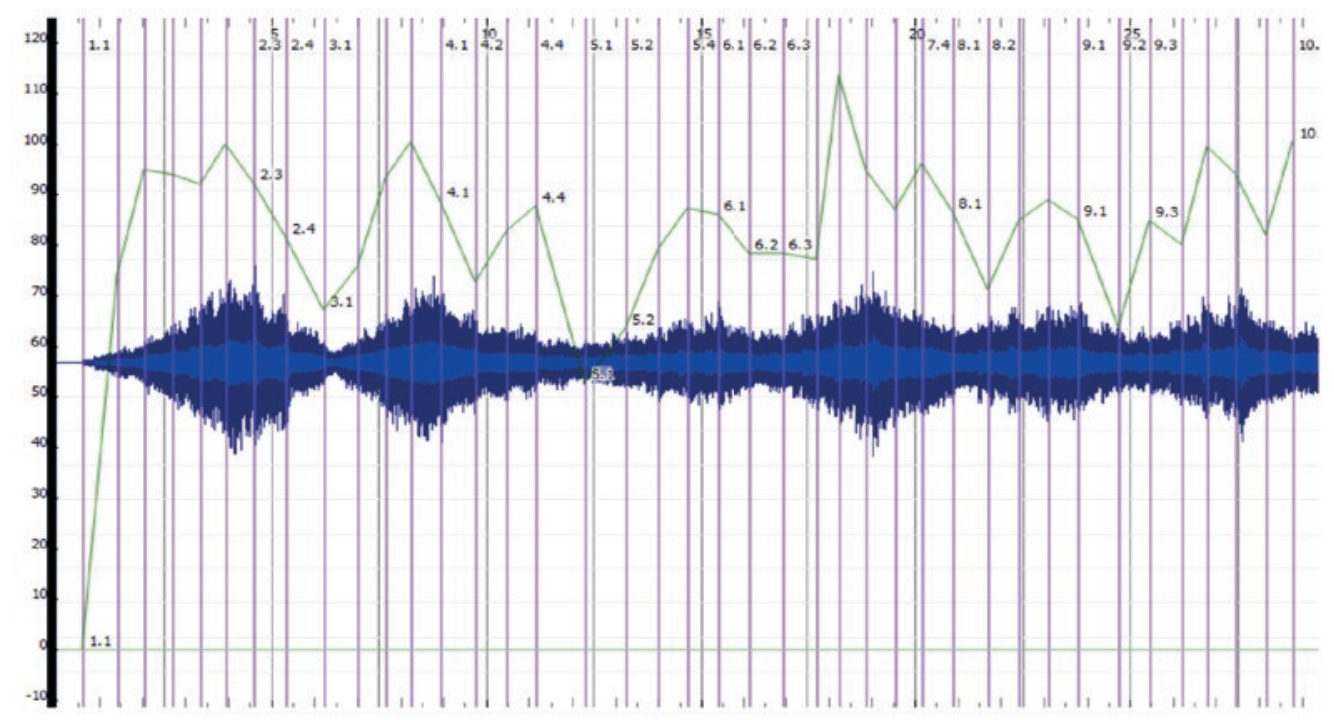

Figura 9: Visualização gráfica do Sonic Visualiser da execução de um dos pianistas da amostra. Forma de onda e gráfico das inflexões do timing (linha verde, c. 1-10). As barras verticais em roxo indicam a pulsação de cada compasso.

Assim, o gráfico delineia as curvas de agógicas que nos permitem avaliar, por exemplo, as conduções de frases e as flutuações de tempo deliberadas ou não deliberadas, ou seja, a condução do discurso musical em tempo real, incluindo o rubato. Esses re- 
cursos proporcionados pelo software podem oferecer dados quantificáveis em relação ao timing de uma execução.

Os dados desse procedimento foram extraídos em formato de texto (.txt) para o Excel, que permitiu observar e comparar as variações de andamento em bpm das gravações. O eixo horizontal dos gráficos mostra o número do compasso e o tempo. Ou seja, a indicação "2.3" significa c. 2, terceiro tempo. O eixo vertical mostra o andamento em valores metronônicos (bpm), sendo que nessa análise a unidade de tempo adotada é a semínima.

Neste trabalho realizamos também o mapeamento das intensidades e para isto foram gerados gráficos que mostram os valores de intensidades permitindo analisar as gravações em relação às dinâmicas. O pluging Power Curve: smoothed power nos permite observar a relação entre tempo e dinâmica de uma execução através de um gráfico da curva de dinâmica, obtido a partir das informações de intensidade do arquivo de áudio. Pesquisas recentes, no entanto, alertam que dados das flutuações de dinâmica ainda não resultam com a mesma precisão do timing. Fatores como instrumento, acústica, equipamento de captação, dentre outros aspectos, influenciam nos valores de intensidades.

\section{Análise das gravações do primeiro movimento da Sonata}

Intérpretes distinguem-se entre si principalmente pela manipulação do tempo. Paradoxalmente, existem diferenças significativas entre interpretações mesmo quando os executantes apregoam sua inquestionável fidelidade ao texto como mostra de sua integridade artística. Dentre essas concepções, o tempo tem uma função primordial na atribuição do caráter e no direcionamento do discurso musical. Segundo Gerling (2008, p. 10), "o tempo é a tela do músico. É o nosso espaço. Podemos mudar de maneira dramática o caráter de uma ideia musical ao mudarmos seu andamento, e consequentemente, o segmento temporal que ocupa". Por sua vez, Matschulat (2011, p. 52) afirma que execuções em andamentos diferentes de uma mesma obra comunicam perfis expressivos distintos e influenciam na comunicação gestual em uma execução.

A partir da comparação dos tempos empregados por quatro pianistas respectivamente designados por EM, MP, JS e HA na interpretação da Sonata n.1 de Francisco Mignone e, tendo em vista a indicação de andamento escolhida pelo compositor, observa-se que os intérpretes realizam mudanças de andamento de uma seção para outra, mesmo Mignone não as tendo especificado. No gráfico 1, é possível observar as diferenças e semelhanças de andamentos adotados pelos intérpretes em cada seção. Nota-se que os pianistas adotaram andamentos diferentes nas seções $A, B, C, B^{\prime}$ e A' em contraposição à uma certa similaridade do andamento na seção $D$, com exceção da execução de MP, bem acima da velocidade escolhida pelos demais intérpretes. 


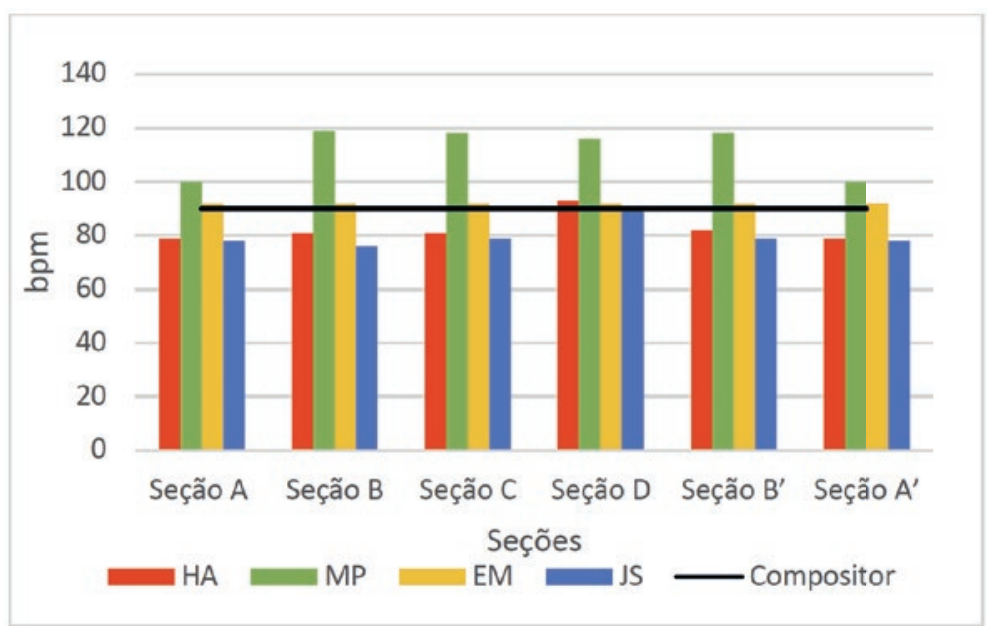

Gráfico 1: Variações de andamentos entre as seções do primeiro movimento da Sonata nas execuções de HA, MP, EM e JS.

Auditivamente podemos não perceber com clareza as mudanças de andamentos entre as seções, no entanto graficamente (Gráfico 1) podemos observar as flutuações do tempo especialmente nas gravações de HA, MP e JS. O gráfico revela claramente a adoção de um andamento mais movido na execução de HA e JS no desenvolvimento (Seção D, c. 58-81), bem como a retomada do andamento anterior na recapitulação (Seção B', c. 82-100). O intérprete designado como MP mantém uma média de andamento mais elevada para todo o movimento e, no desenvolvimento (Seção D, c. 58-81) diminui sutilmente $o$ andamento.

Segundo Santos, Gerling e Bortoli (2012, p. 150), as inflexões rítmicas ou variações do timing são pequenos desvios realizados pelos intérpretes na projeção expressiva das estruturas rítmicas de uma obra. Tais inflexões quando deliberadas e intencionais acontecem devido à manipulação da velocidade entre os eventos estruturais do tempo, sem extrapolar a métrica, mas com o propósito claro de salientar alguma nuance expressiva tanto na micro quanto na média ou mesmo, na macro estrutura. A partir da análise da partitura e da escuta das gravações selecionei alguns trechos para comparação das gravações, a fim de observar as inflexões deliberadas de timing e diferenças na comunicação expressiva de cada execução. Por meio desses parâmetros pode-se visualizar a flexibilidade do tempo nas gravações, considerando que os dados de pulsação são utilizados para entender a flutuação de timing nos compassos, frases ou seções.

\section{Trecho 1 (c. 1-10)}

O evento inicial da peça, delimitado entre os compassos 1 à 10, revela ideias interpretativas similares entre os intérpretes. No trecho 1 da seção A (c. 1-10, figura 10), há uma formação de oitavas graves no baixo (m.e.) que apoiam o ostinato de notas curtas e de figuração reiterada (m.d.) característica da apresentação do tema 1. 


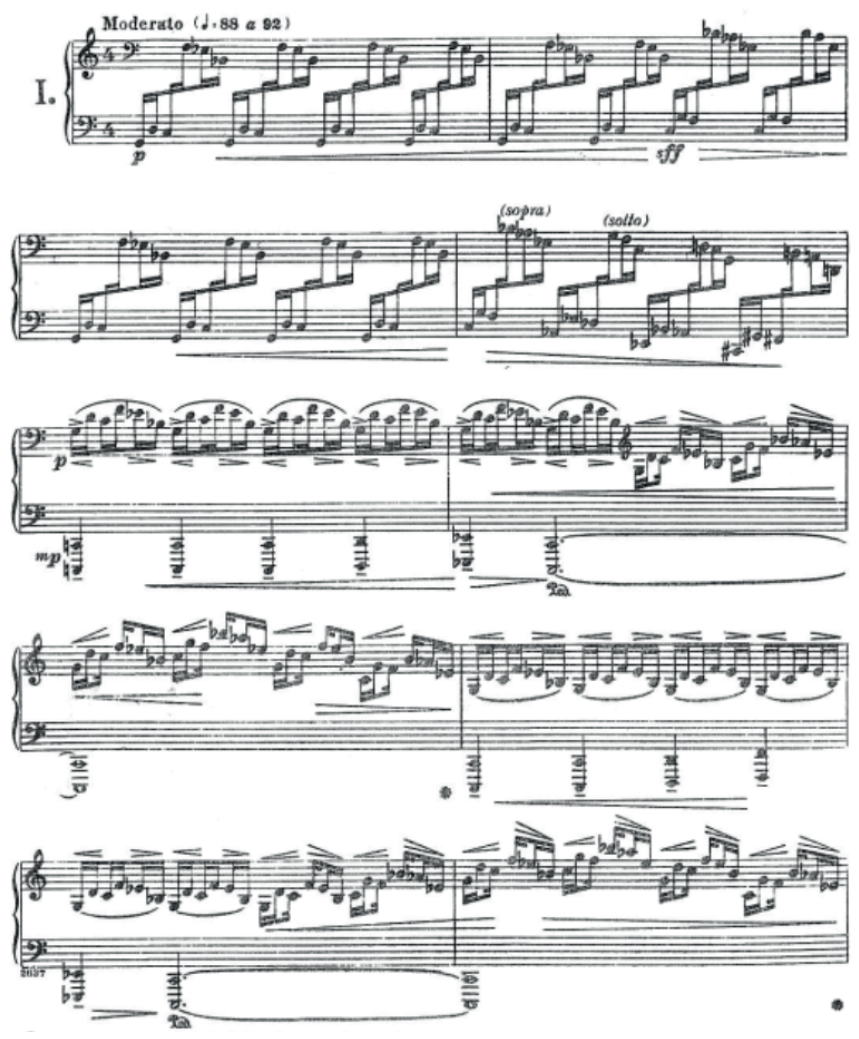

Figura 10: Seção A, c. 1-10 do primeiro movimento da Sonata.

O gráfico 2 mostra a descrição temporal desse trecho (Figura 10), selecionado a fim de demonstrar como a indicação de tempo inicial é projetada pelos intérpretes. De forma geral, observa-se similaridade no contorno da linha do tempo dos pianistas, no entanto percebe-se diferenças de inflexões de timing em um mesmo compasso. Nota-se também um padrão de aceleração e desaceleração de dois em dois compassos na introdução (c. 1-4) e de três em três compassos nas frases seguintes (c. 5-7 e c. 8-10). Assim, constata-se que as interpretações de EM, MP e JS apresentam um perfil mais angular, com oscilações temporais mais frequentes. 


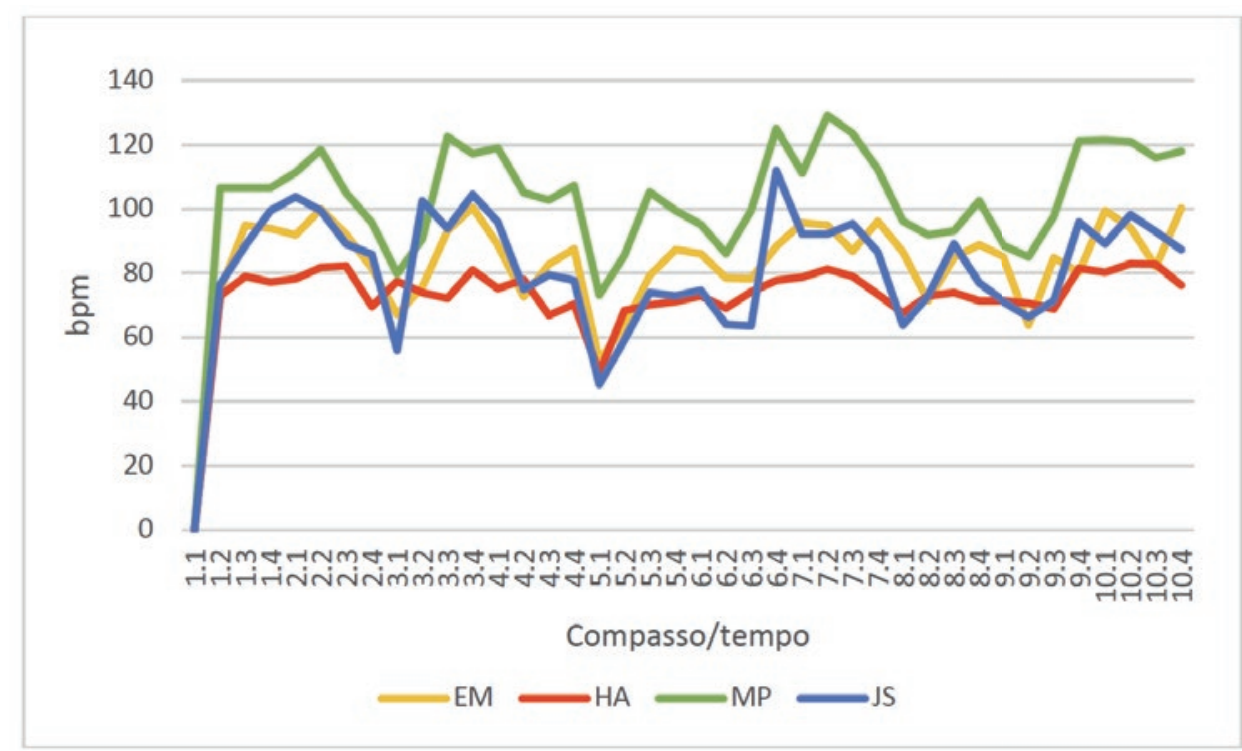

Gráfico 2: Inflexões do timing no trecho 1 (c. 1-10).

Nas duas semifrases do evento inicial (c. 1-2 e c. 3-4), tanto no final do c. 2 quanto no final do c. 4, observa-se um desacelerando comumente executado pelos pianistas, por sua vez, mais acentuado na segunda semifrase (c. 3-4).

Nesse trecho (c. 1-4), MP realiza um apoio dinâmico na primeira nota de cada grupo de seis semicolcheias do ostinato, pedalizando-o de forma sutil, evidenciando a escolha por uma execução mais articulada na comparação com as demais interpretações desta amostra. Por outro lado, EM, JS e HA articulam o ostinato de forma menos articulada e pedalizam os grupos de seis notas mais continuamente do que MP, explicitando um crescendo mais encorpado nesse evento inicial.

Auditiva e graficamente (Gráfico 2) observa-se um acelerando compartilhado pelos intérpretes do terceiro para o quarto tempo do c. 6 e 7 e do terceiro para o quarto tempo do c. 9 e 10, nos quais a mão esquerda sustenta o Dó no grave enquanto a mão direita continua executando a figuração do ostinato em movimento ascendente e descendente. Nas interpretações de JS e MP, esse acelerando é mais realçado.

A execução do material melódico-temático da mão esquerda (c. 5-10, figura 10) apresenta diferenças interpretativas em relação à condução do fraseado. EM, JS e MP direcionam o fraseado de modo a realizar um crescendo até a nota Mib (primeiro tempo do c. 6 e 9) e um decrescendo para a nota longa (Dó, segundo tempo do c. 6 e 9). $\mathrm{Na}$ execução de HA, a nota longa é mais pronunciada do que o Mib no tempo forte do compasso. Ou seja, o direcionamento fraseológico deste intérprete parece ser a chegada na nota longa, sustentada por sete tempos, considerando a ligadura de valor.

As inflexões de timing na execução de HA (c. 1-10) revelam-se mais equalizadas, enquanto as linhas do tempo de MP, EM e JS apresentam mais picos de andamento, evidenciando uma preocupação com a flexibilidade de tempo e com mais nuances na dinâmica. Segundo Santos, Gerling e Bortoli (2012, p. 156), a manipulação das inflexões rítmicas estão relacionados tanto ao desvio do tempo de ataque da nota como também das implicações de articulações e dinâmicas. 
Os pianistas EM e JS manipulam os eventos musicais desse trecho por meio de manipulações de articulação e pedalização. Ambos utilizam o recurso do pedal para efeitos sonoros e nuances expressivas de dinâmicas. Por outro lado, HA e MP utilizam o pedal de forma moderada, evidenciando suas escolhas por interpretações mais articuladas e cristalinas.

Com o pluging Power Curve: smoothed power, foram confeccionados gráficos que nos permitem observar a relação entre tempo e dinâmica nas execuções desta amostra. Observa-se similaridade na construção expressiva da dinâmica entre os intérpretes e uma clara correlação do tempo e da dinâmica (Figura 11). A impressão geral é que quando há um aumento do andamento há também um crescendo da dinâmica e quando há um diminuendo do andamento há um decrescendo da dinâmica. Esse recurso expressivo é comumente executado pelos intérpretes no repertório musical para conduzir e delinear o fraseado.

a)

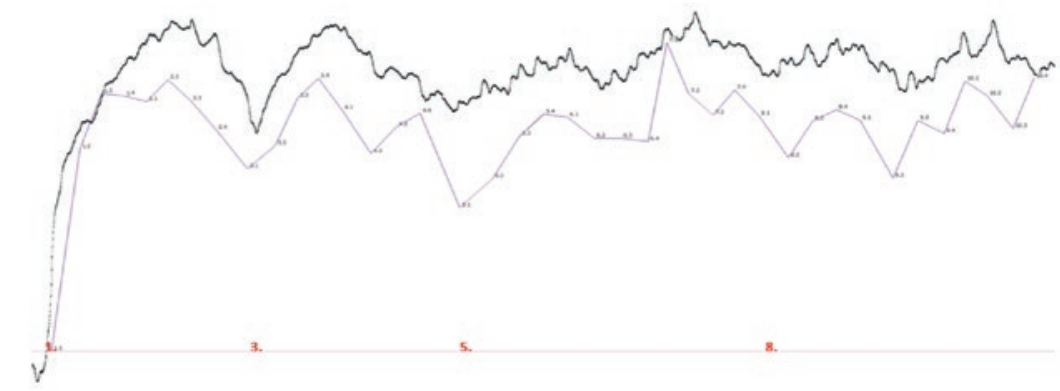

b)

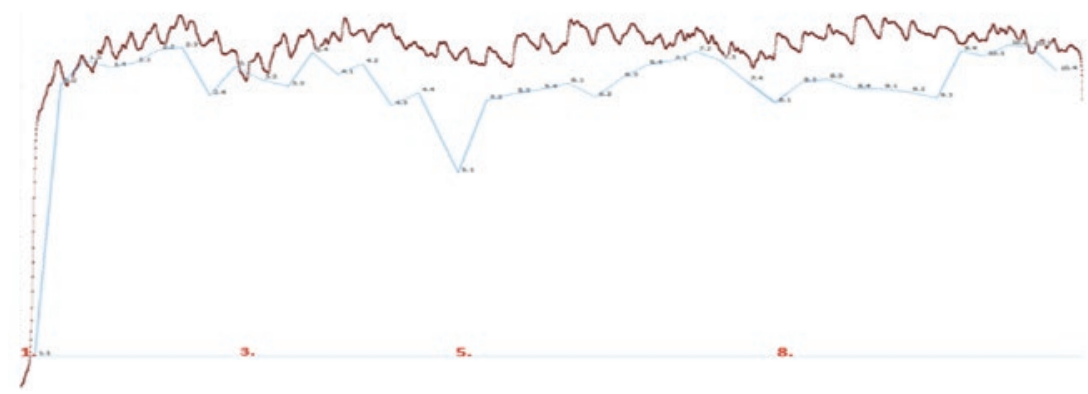

c)

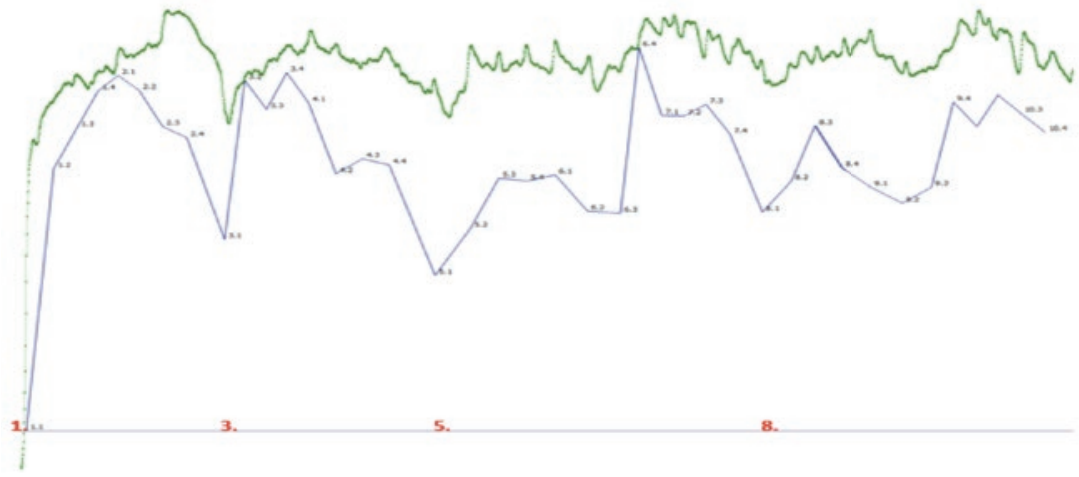


d)

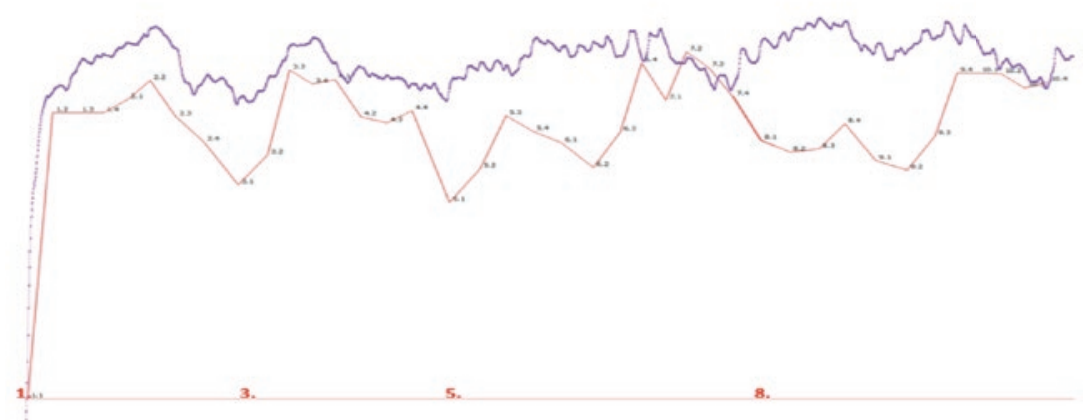

Figura 11: Relação do tempo e da dinâmica nas execuções dos intérpretes: (a) EM; (b) HA; (c) JS; (d) MP - a linha superior indica a curva de dinâmica, a linha inferior indica a curva do tempo e em vermelho a numeração dos compassos.

Observa-se um elevado grau de intencionalidade no delineamento do fraseado nos compassos 1-2, 3-4, 5-7, 8-10, sendo que os intérpretes desta amostra manipulam tanto o tempo quanto a dinâmica nos finais das frases, direcionando-as para uma condução deliberada.

\section{Trecho 2 (c. 21-31)}

Nesse trecho (c. 21-31), o evento inicial no c. 21 (acorde acompanhado pela apogiatura Réb no grave, figura 12) aparece com mais de um onset ${ }^{8}$ na gravação, caso este que a nota ornamental é tocada antes do acorde. Nesse contexto, para fins de padronização dos dados consideramos o instante do ataque do acorde no tempo forte do compasso.

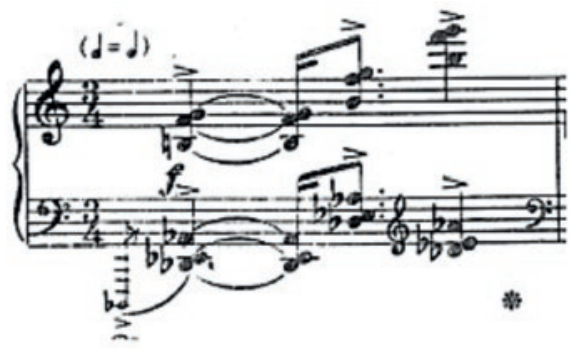

Figura 12: c. 21.

Como analista, assinalar os tempos nesse trecho envolveu maior atenção visto que os intérpretes optaram por agrupar a figuração rítmica da mão esquerda segundo o padrão de execução da nota mais aguda em direção à nota mais grave e não o grupo de quatro semicolcheias (Figura 13). Com o recurso de desaceleração do áudio do Sonic Visualiser foi possível ouvir onde inicia a primeira nota de cada grupo de quatro semicolcheias, ou seja, quando o tempo um, dois e três de cada compasso inicia, justamente devido a escolha interpretativa dos pianistas quanto à articulação dos agrupamentos rítmicos. 


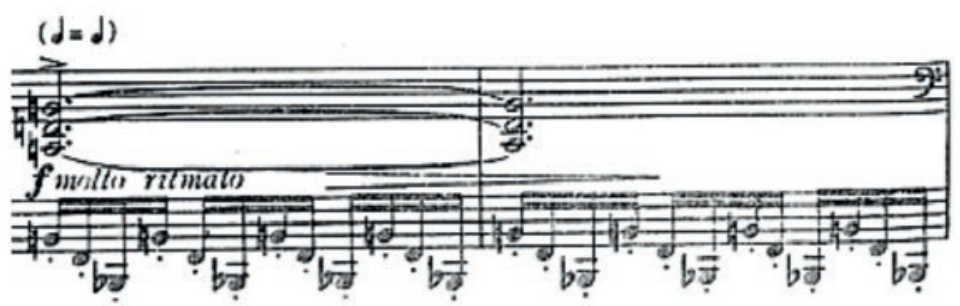

Figura 13: c. 22-23.

De acordo com o gráfico 3, pode-se afirmar que as gravações apresentam similaridade na condução e inflexão do timing nesse trecho (c. 21-31), embora nem sempre convergentes. A gravação de HA e JS assemelham-se quanto às flutuações de tempo, ou seja, apresentam pulsações mais uniformes, enquanto o contorno da linha do tempo das execuções de MP e EM mostram mais picos de andamento, inclusive em um mesmo compasso.

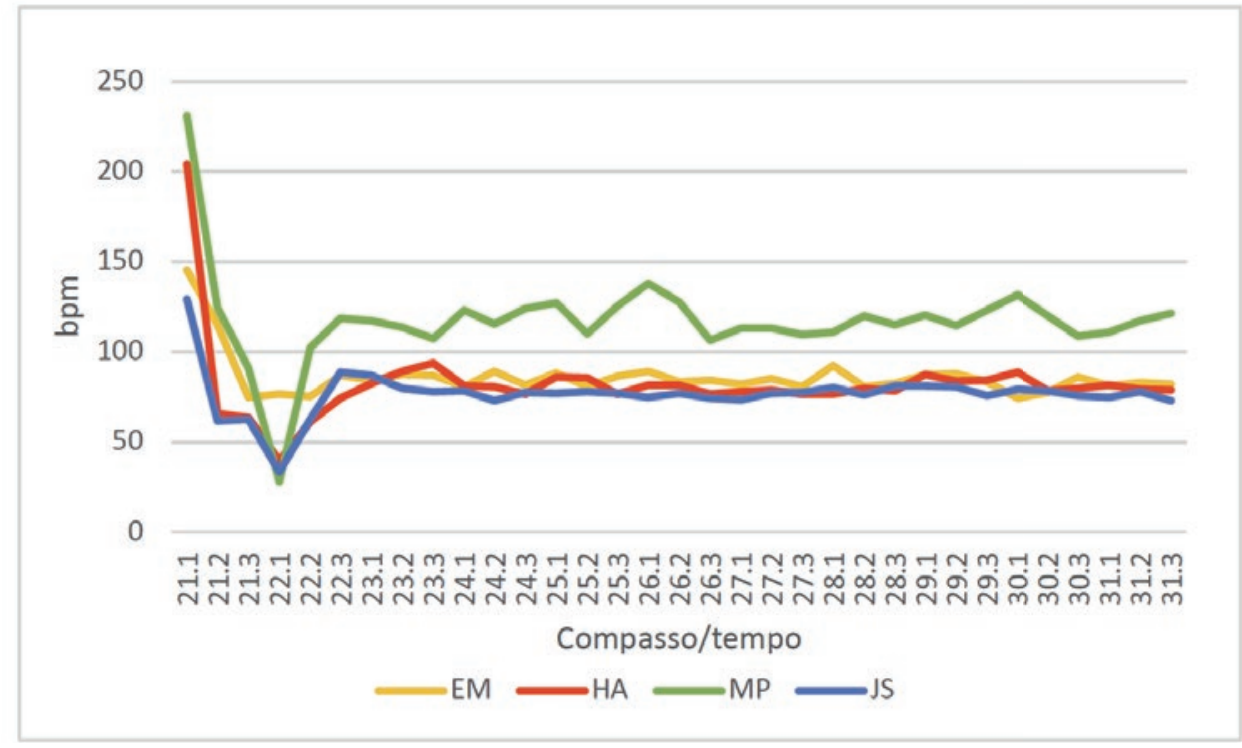

Gráfico 3: Inflexões do timing no trecho 2 (c. 21-31).

Observa-se nas linhas do tempo das execuções de HA, MP e JP uma considerável diminuição do andamento do terceiro tempo do c. 21 para o primeiro tempo do c. 22. Nesse trecho ocorre súbita modificação no discurso musical, ou seja, há uma quebra de padrão, o desenho rítmico e melódico que interliga as seções $A$ e B (c. 21) é anômalo. Por outro lado, a execução de EM, mantém o tempo constante, o que significa que o pianista não espera tanto tempo para iniciar a seção B (c. 22-39) como o fazem HA, MP e JP. Na sua execução, MP imprime uma ênfase temporal muito significativa a esta passagem e espera $(0,819$ s) para iniciar a próxima seção (Seção B, c. 22-39). O intérprete também realiza uma breve interrupção sonora no final do c. 21 , evidenciada por uma precisa troca de pedal prescrita pelo compositor.

A ambiguidade inerente ao desenho rítmico do ostinato da seção B (c. 22-39, mão esquerda) demanda algumas decisões interpretativas. Isso se confirma ao analisarmos 
as gravações e percebermos escolhas interpretativas diferentes em relação ao agrupamento das notas na mão esquerda (Figura 14).

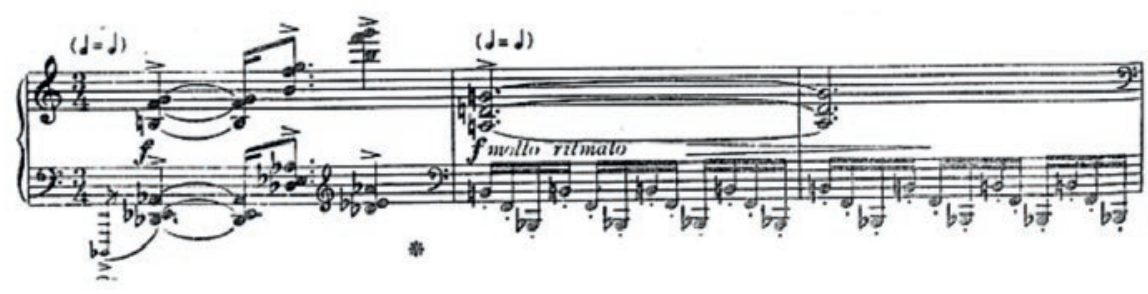

Figura 14: Trecho 2 (c.21-23).

Observa-se três diferentes formas de execuções desse ostinato: 1) MP realça o agrupamento de três em três notas ao realizar um apoio dinâmico equalizado em cada uma delas; 2) JS articula o agrupamento de três notas e apoia na nota mais grave de cada grupo (Sib); 3) EM e HA articulam o grupo de três notas com apoio na nota mais aguda, Sił, no entanto a articulação em staccato do grupo de três notas é ofuscada pela pedalização sincopada dos intérpretes.

Ressalta-se que as execuções de EM e HA, mesmo utilizando uma pedalização mais constante, não deixam de articular o staccato. Por outro lado, JS apresenta uma interpretação mais límpida, com pedalização mais esparsa, especialmente na sequência de notas repetidas da mão direita da seção B (Fá, c. 24-25, 28-29 e Láb, c. 32-33, figura 15). A gravação de MP, por ser mais rápida, apresenta uma realização mais pronunciada dos eventos rítmicos, principalmente os ostinatos da mão esquerda nas seções B (c. 2239) e C (c. 40-57).

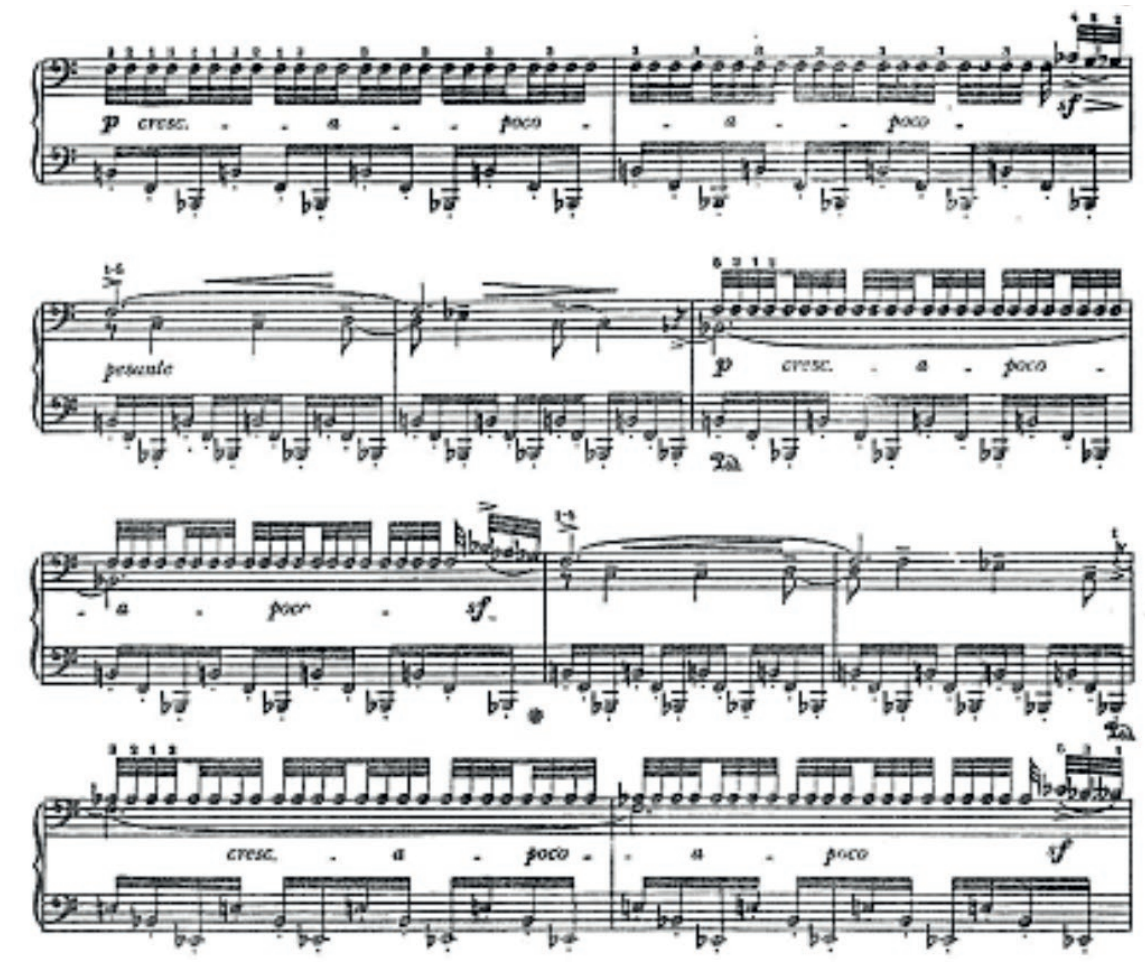

Figura 15: Seção B (c. 24-33) do primeiro movimento da Sonata. 
Ao analisar dez performances do Ponteio n. 49 de Camargo Guarnieri Matschulat (2011, p. 53) afirma que a articulação é diretamente relacionada ao andamento. Em sua pesquisa constatou uma tendência das interpretações mais rápidas serem mais articuladas, evidenciando um caráter mais percussivo. Essa observação se confirma como tendência nas gravações selecionadas neste presente trabalho, especialmente a interpretação de MP.

A expressividade dinâmica foi analisada nesse trecho tanto nas formas de ondas quanto nas curvas suavizadas de dinâmicas, que permitem a visualização da amplitude de intensidade sonora das execuções (Figura 16). Observa-se que o formato paralelo do tempo e da dinâmica é particularmente mais claro na execução de MP, enquanto que nas demais execuções o movimento da curva de dinâmica e do tempo apresentam maior grau de diferenciação. Na representação gráfica de MP observa-se claramente a separação do final do c. 21 para o início do c. 22, como citado anteriormente (destaque em vermelho, figura $16 \mathrm{~d}$ ).

a)
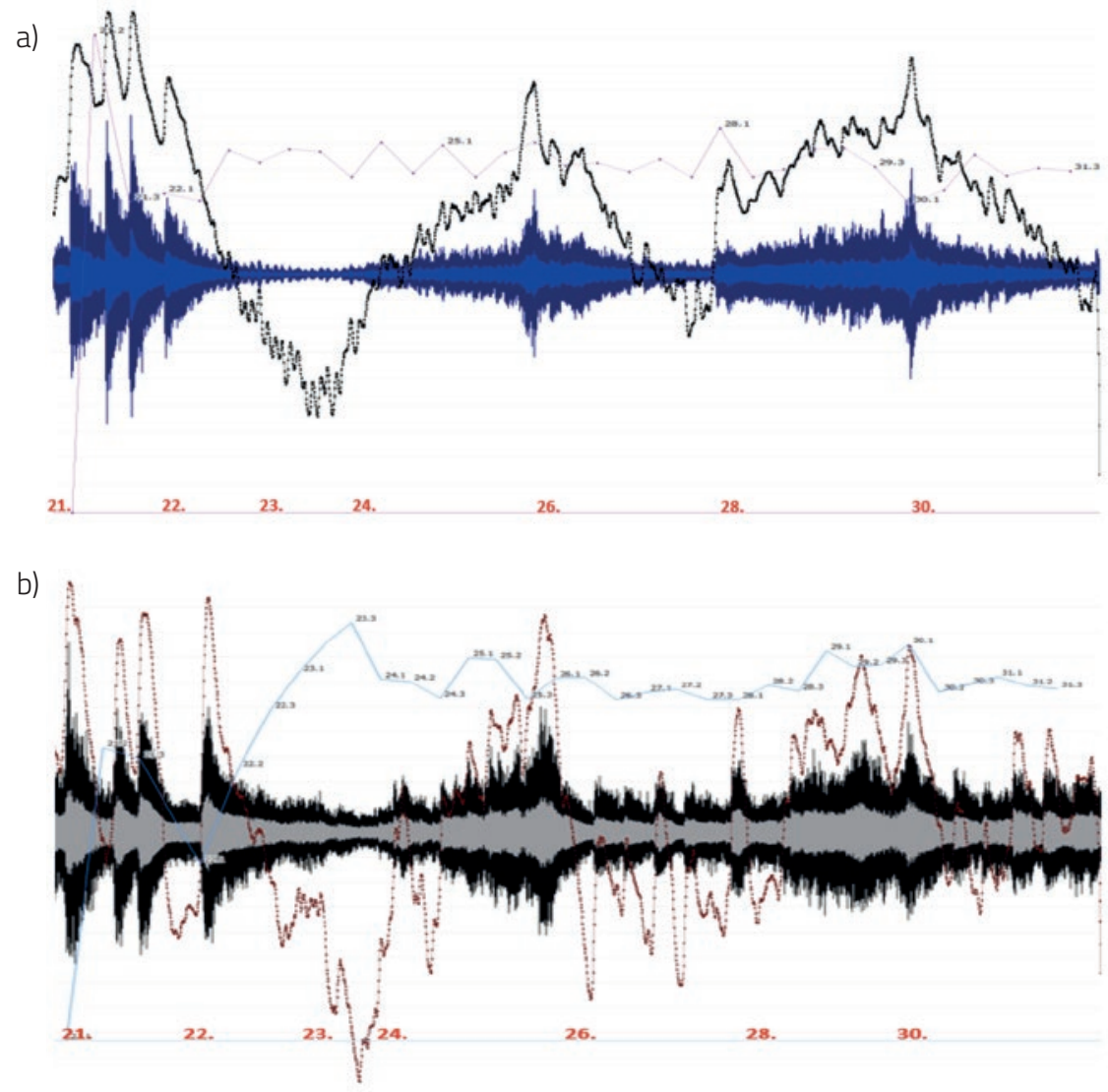
c)

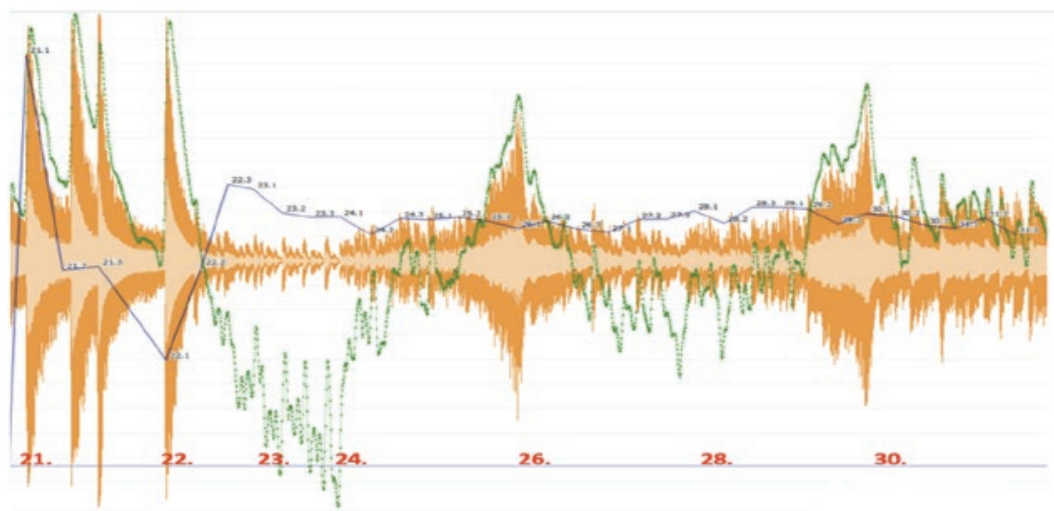

d)

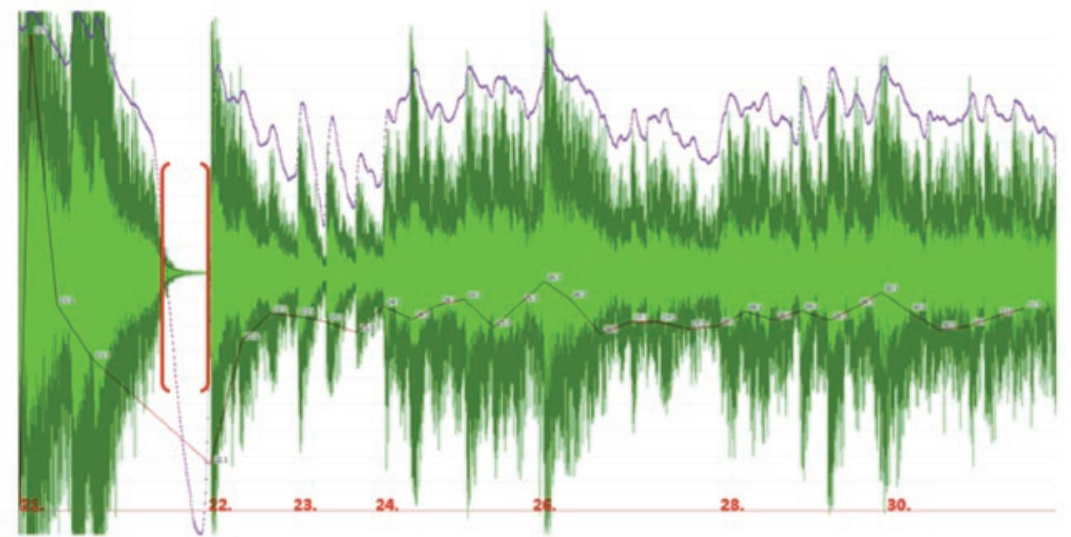

Figura 16: Relação do tempo e da dinâmica nas execuções dos intérpretes: (a) EM; (b) HA; (c) JS; (d) MP - a linha superior indica a curva de dinâmica, a linha inferior indica a curva do tempo, forma de onda e em vermelho a numeração dos compassos.

Observando a curva geral de amplitude, pode-se constatar que a execução de EM apresenta uma forma de onda e uma curva de dinâmica com nuances claras da amplitude sonora que condiz com as indicações de Mignone na partitura. É visível o delineamento frasealógicos dos quatro intérpretes por meio das nuances de dinâmicas, especialmente na realização do decrescendo do segundo tempo do c. 22 para o c. 23, assim como no direcionamento do crescendo e decrescendo nas duas frases seguintes (c. 24-27/ 28-31).

\section{Trecho 3 (c. 38-43)}

O trecho 3 (Figura 17) compreende os dois últimos compassos da seção B (c. 3839) e os quatro primeiros compassos da seção $C$ (c. 40-43). A escolha desse trecho se deu ao constatar um desacelerando compartilhado pelos quatro intérpretes para iniciar a seção C (c. 40-57) ainda que Mignone não tenha fornecido qualquer indicação de ritardando na partitura. 


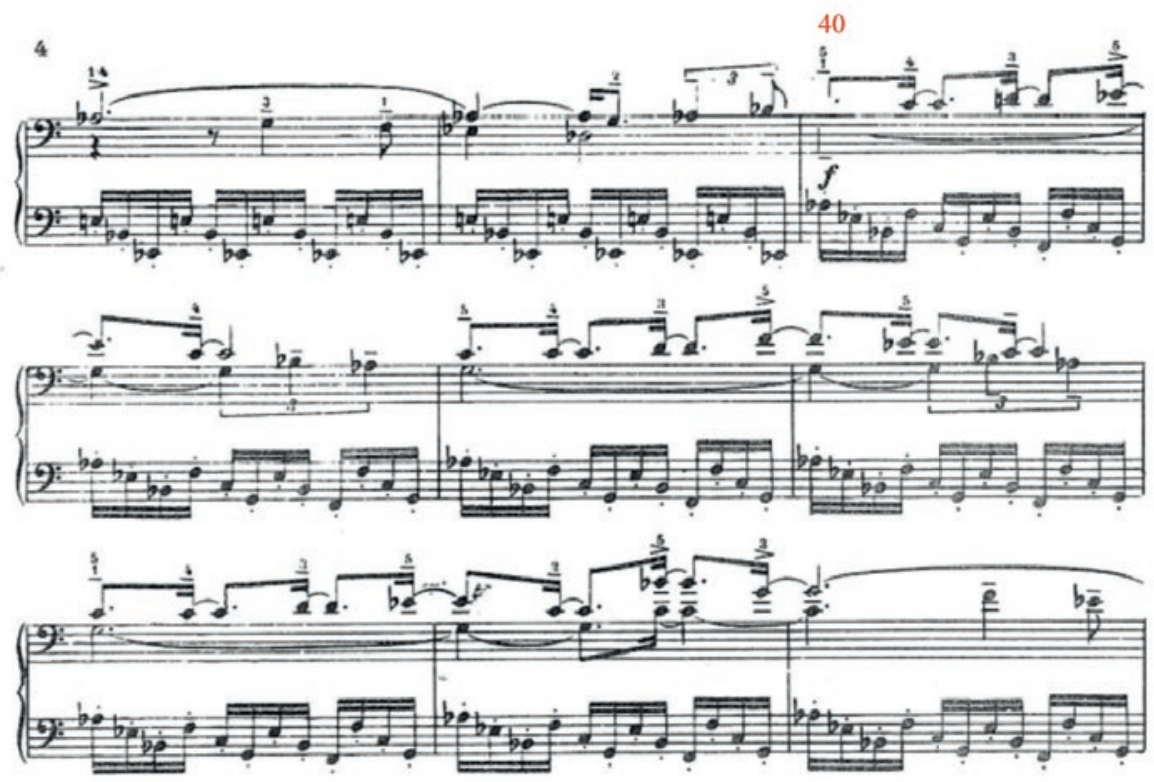

Figura 17: Trecho da Seção C (c. 38-43) do primeiro movimento da Sonata.

O gráfico 4, confirma essa escolha interpretativa coincidente e permite constatar uma diminuição do andamento do terceiro tempo do c. 39 para o primeiro tempo do c. 40 nas gravações desta amostra. É notória a intenção de reduzir o andamento no final desse compasso. Observa-se também que a linha do tempo de MP apresenta mais picos de andamento em relação às demais interpretações, o que significa que sua condução é mais flexível neste trecho.

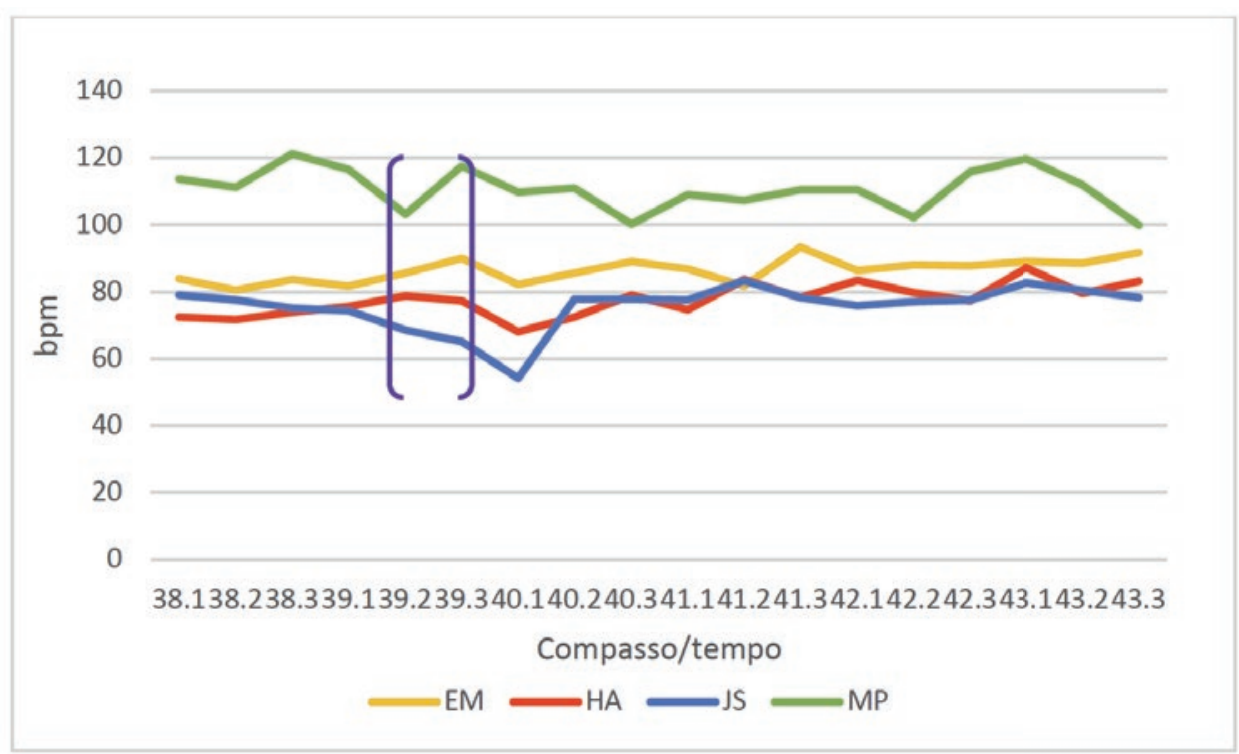

Gráfico 4: Inflexões do timing no trecho 3.

Auditiva e graficamente, percebe-se a diminuição do andamento na passagem entre as duas seções (c. 39-40) nas execuções de EM, MP e HA. Os três intérpretes realizam 
uma sutil desaceleração no c. 39, enquanto JP realiza um ritardando mais enfático desde o primeiro tempo do c. 39, retomando o andamento ao iniciar a seção C (c. 40-57).

As ideias interpretativas dos pianistas em relação ao timing nesse trecho são praticamente semelhantes. No entanto, embora exista uma relativa proximidade das linhas do tempo das execuções de EM e HA, é interessante observar que EM manipula o tempo de maneira inversa a HA nos compassos 41-43 (Gráfico 5). No c. 41, o ponto mais lento na linha do tempo de HA é o ponto mais rápido na linha do tempo de EM, seguido pela desaceleração de HA em direção ao segundo tempo do c. 42 e aceleração para o primeiro tempo do c. 43, em contraposição ao equilíbrio do tempo na execução de EM.

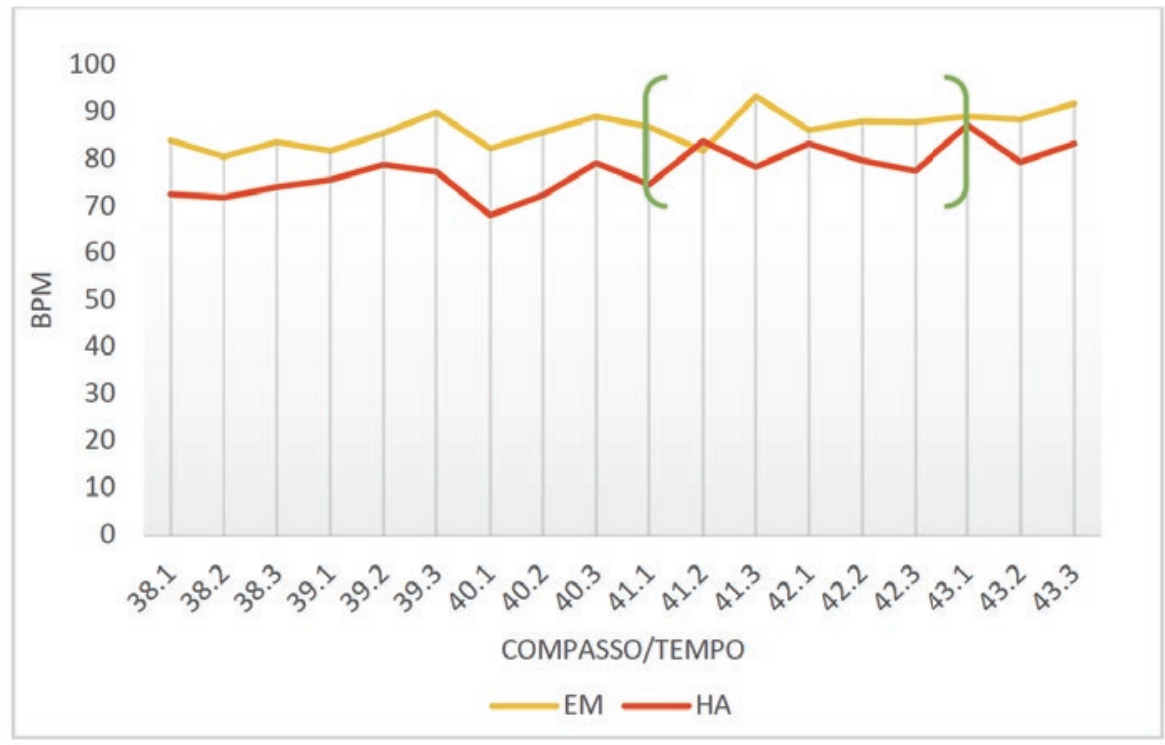

Gráfico 5: Inflexões do timing de EM e HA no trecho 3.

Os apoios dinâmicos do ostinato no trecho 3 (c. 38-43) apresentam algumas diferenças quanto a articulação e o agrupamento das notas. Na execução de EM, todas as notas são articuladas em staccato e a condução do fraseado do ostinato é realizada de acordo com o fraseado da melodia na mão direita. Por outro lado, HA executa o ostinato mais pedalizado do que EM, agrupando as notas de três em três semicolcheias. JS e MP, além de executarem as notas bem articuladas em staccato também conduzem o fraseado do ostinato enfatizando a nota Láb do primeiro tempo de cada compasso. Em relação ao delineamento fraseológico da voz superior, os intérpretes compartilham escolhas interpretativas similares ao agruparem o fraseado de dois em dois compassos.

$\mathrm{Na}$ figura 18, observa-se o delineamento fraseológico de dois em dois compassos em todas as execuções. Detalhadamente, nota-se um decaimento mais acentuado da dinâmica no final do c. 39 nas execuções de HA, JS e MP, seguido pela condução frasal de dois em dois compassos com crescendo em direção aos c. 41 e 43 e um decrescendo no final em direção à seção C (c. 40-56). 
a)

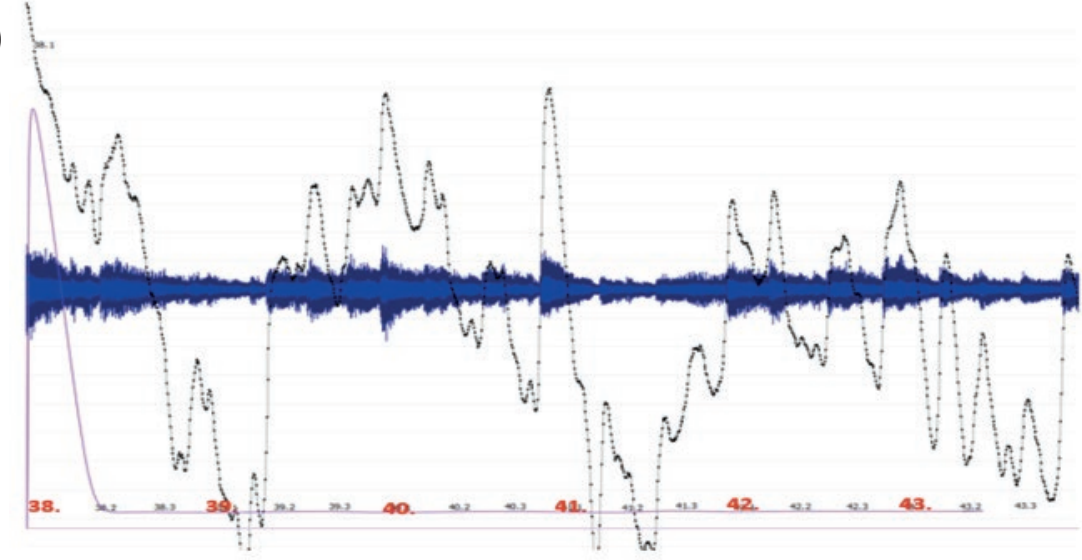

b)

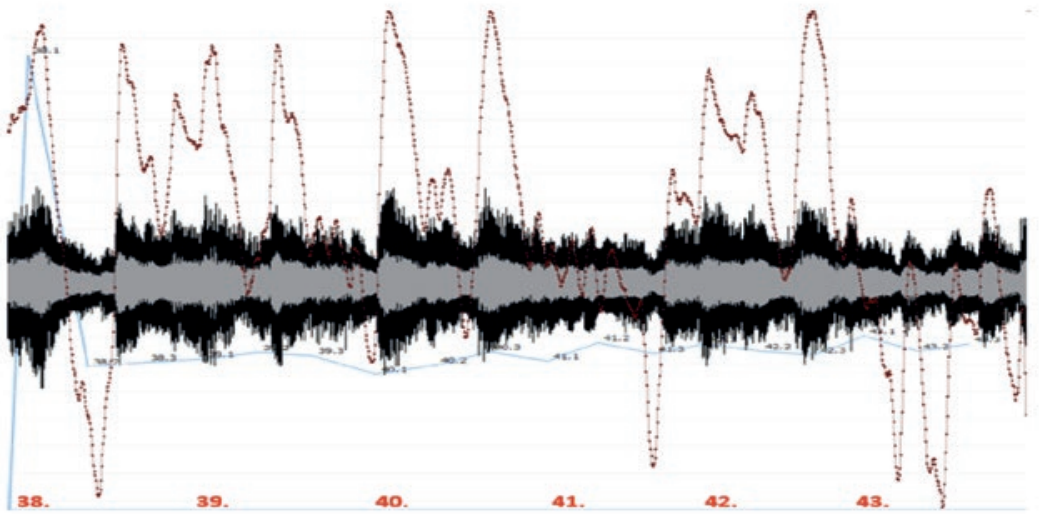

c)

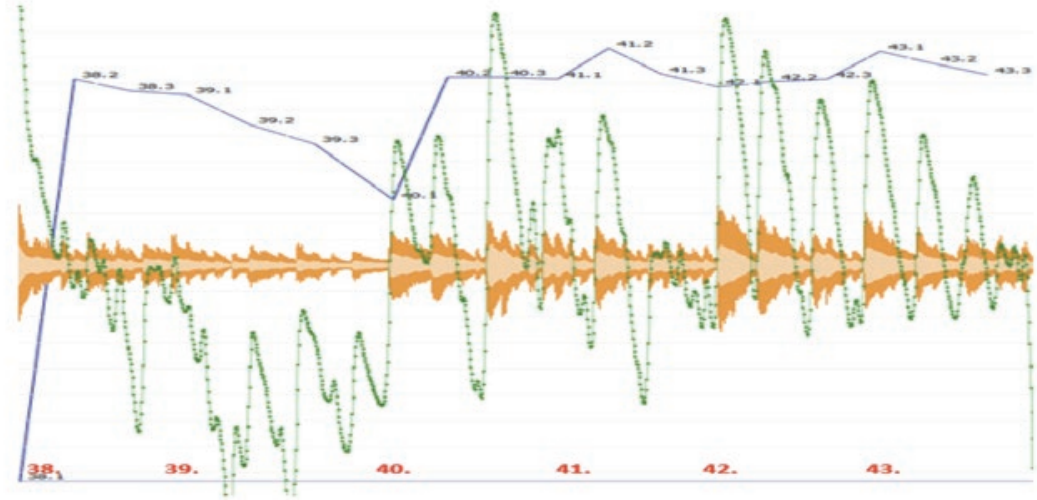

d)

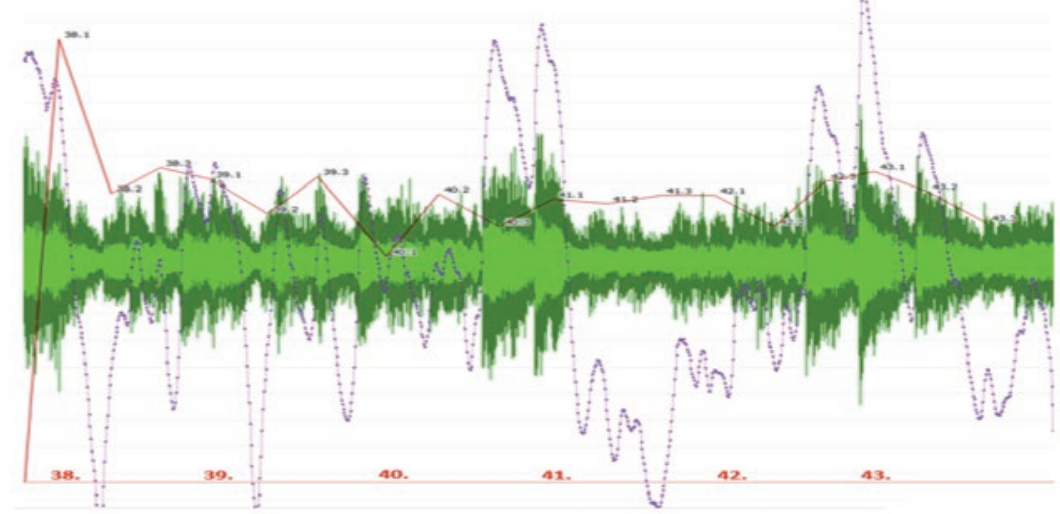

Figura 18: Relação do tempo e da dinâmica nas execuções dos intérpretes: (a) EM; (b) HA; (c) JS; (d) MP - a linha superior indica a curva de dinâmica, a linha inferior indica a curva do tempo, forma de onda e em vermelho a numeração dos compassos. 
Ao comparar a representação gráfica de JS (Figura 18c) com a dos demais intérpretes, observa-se a correlação do tempo e da dinâmica nos c. 38-39, particularmente a ênfase conferida ao diminuendo e ao ritardando no c. 39, bem como uma distinta diferenciação de intensidade sonora no início da seção C (c. 40-57) assinalada em forte na partitura.

\section{Trecho 4 (c. 62-69)}

O trecho 4 é parte integrante da seção denominada desenvolvimento (Seção D, C. 58-81), composta pelo ostinato em legato na mão esquerda (tríades diatônicas ascendentes e descendentes) e pelo material melódico-temático na mão direita, estruturado em semifrases de dois compassos. Sobre o legato no piano (notas sucessivas sobrepostas), Repp (1997) e Bresin (2000) concordam que a articulação depende do direcionamento melódico como estratégia para realçar a expressividade. Os autores observaram que os padrões melódicos descendentes são, geralmente, tocados com mais sobreposição do que os padrões ascendentes. Considerando a troca de modo (Dó Eólio para Dó Jônio), a mudança de articulação do ostinato para legato e os registros do instrumento pelo qual se desenvolve essa seção, a audição das gravações revela a convergência das ideias dos intérpretes ao criar uma sonoridade delicada e ingênua como a principal característica desse trecho (Figura 19).

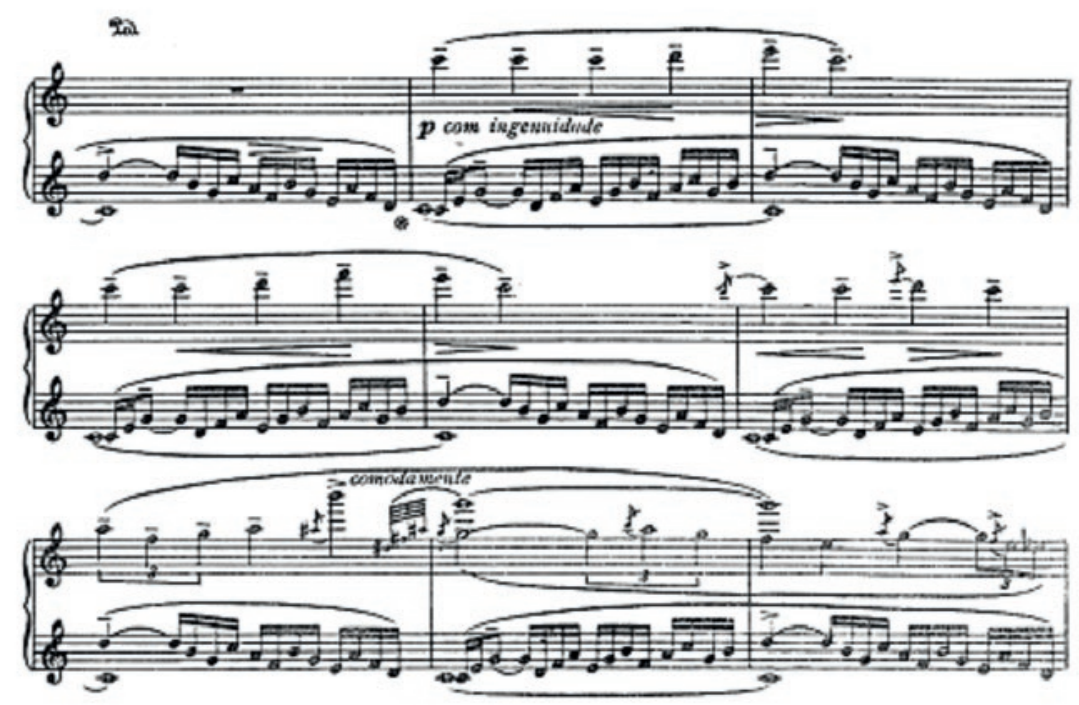

Figura 19: Trecho 4, c. 61-69.

De acordo com o gráfico 6, os intérpretes apresentam formas diferentes de lidar com as nuances temporais, observação esta que mantém sua validade nas microestruturas. A linha do tempo da execução de MP e HA apresentam mais picos de andamento do que as demais. Isto pode evidenciar um grau mais elevado de flexibilidade em relação à condução do tempo. Auditiva e graficamente constata-se que onde não há atividade da mão direita, por exemplo, nos compassos 63 e 65, os intérpretes aceleram ligeiramente o andamento do ostinato na mão esquerda. Observa-se um perfil de curva descendente acentuada na linha do tempo de MP e HA do quarto tempo do c. 67 para o 
primeiro tempo do c. 68 , evidenciando uma desaceleração do andamento, bem como uma preparação sonora para alcançar a nota Sol no tempo forte do c. 68. Essa preparação, tanto do tempo quanto da dinâmica, parece ocorrer em função da ornamentação que precede a nota Sol em oitava na mão direita e à indicação verbal "comodamente", o que justifica a execução mais calma de ambos os pianistas em relação aos demais.

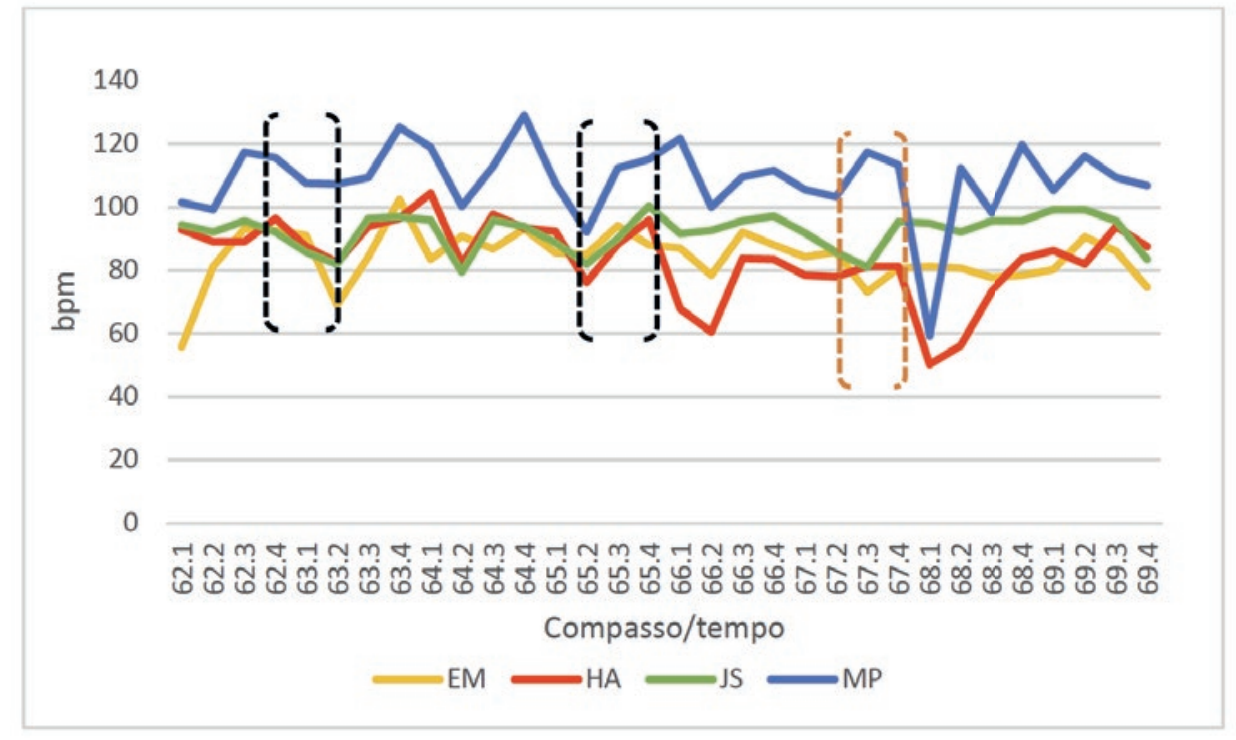

Gráfico 6: Inflexões do timing no trecho 4.

Auditivamente nota-se a acuidade expressiva dos intérpretes no delineamento da linha melódica desse trecho. No geral, os intérpretes procuram delinear o fraseado desse trecho em semifrases de dois compassos e em determinados momentos a correlação do tempo e da dinâmica é particularmente clara como, por exemplo, na execução de MP (Figura 20).

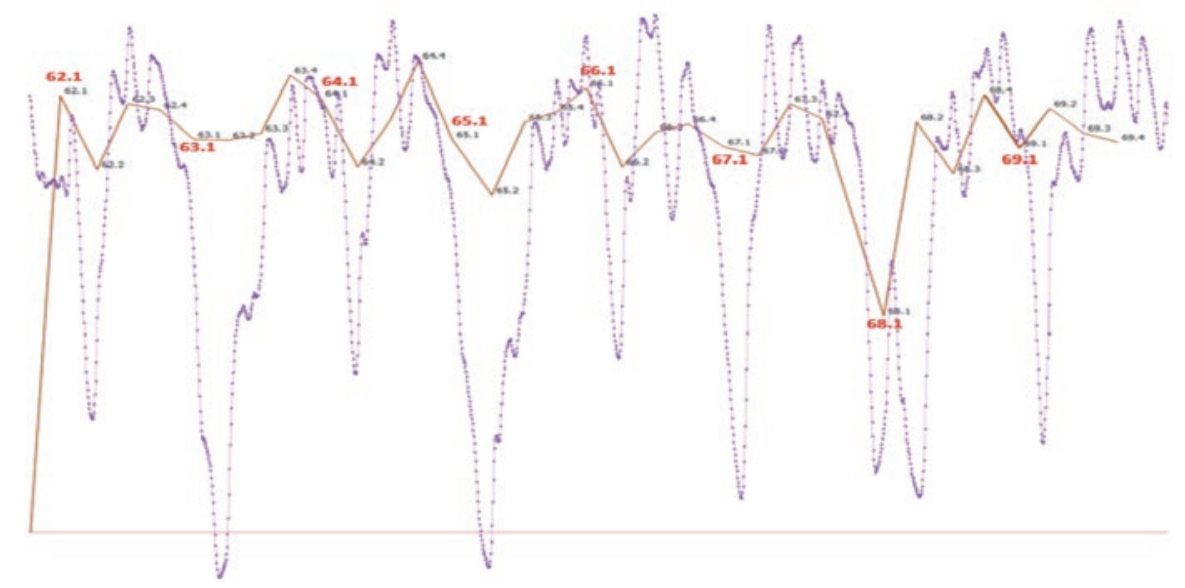

Figura 20: Relação do tempo e da dinâmica na execução de MP (trecho 4, c. 62-69).

Graficamente constatam-se nuances expressivas de timing e dinâmica entre uma nota e outra, como na execução de JS (Figura 21). Por outro lado, as nuances são sutis. Observando a curva do tempo do intérprete (linha azul), nota-se que a nota Dó no pri- 
meiro tempo do c. 62 é mais alongada enquanto o segundo Dó é encurtado. Há um desacelerando do primeiro ataque para o segundo ataque da mesma nota. Prosseguindo, há um pequeno acelerando no ataque do próximo Dó no terceiro tempo, seguido de um desacelerando em direção ao Dó no segundo tempo do c. 63. Intenções expressivas semelhantes são replicadas nos próximos dois compassos (c. 64-65).

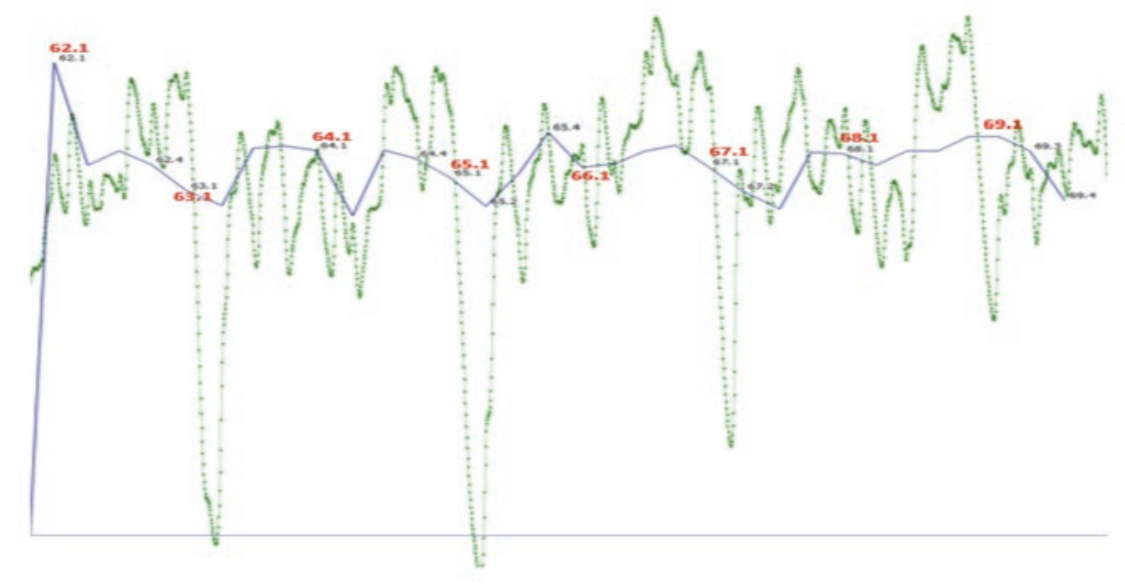

Figura 21: Relação do tempo e da dinâmica na execução de JS (trecho 4, c. 62-69).

O mesmo direcionamento fraseológico das semifrases de dois compassos é comumente executado pelos quatro intérpretes, salvo pequenas diferenças de nuances expressivas entre os ataques das notas dentro de um mesmo compasso. Na figura 22, observa-se que a execução de HA diferencia da execução de JS e MP logo nos primeiros tempos do c. 62. Nesta passagem, HA realiza a nota Dó no primeiro tempo um pouco menos alongada, seguido por um acelerando em direção a nota Ré no quarto tempo do mesmo compasso. $O$ ataque do Ré é mais prolongado e há um desacelerando em direção a nota Dó no final da semifrase no segundo tempo do c. 63 . Como anteriormente mencionado JS, MP e HA realizam um acelerando no ostinato da mão esquerda nos $\mathrm{C}$. 63 e 65, na ausência de atividade melódica da mão direita.

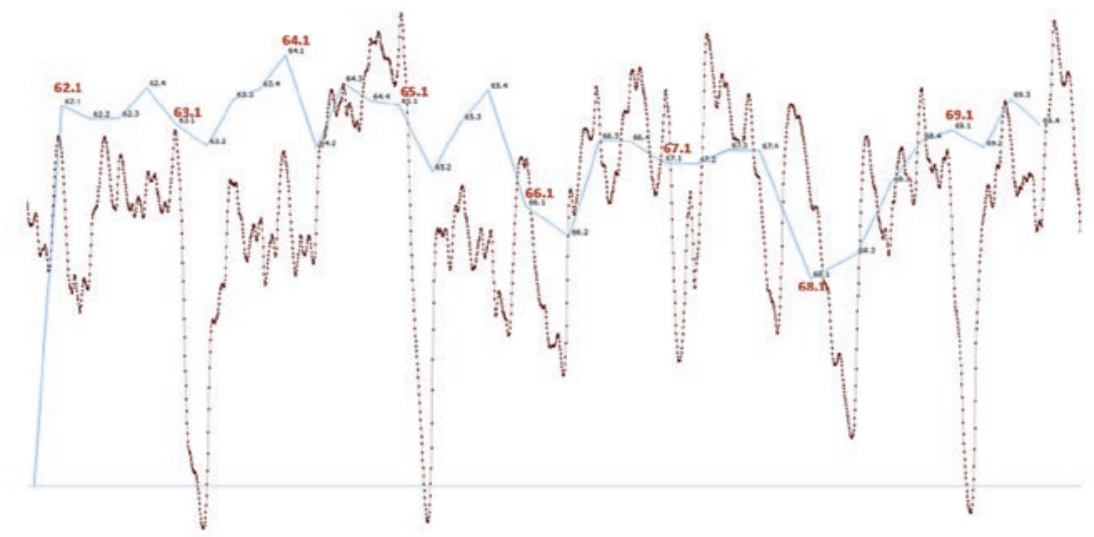

Figura 22: Relação do tempo e da dinâmica na execução de HA (trecho 4, c. 62-69). 
A execução de EM, difere dos demais intérpretes em relação às primeiras notas do c. 62 (Figura 23). EM realiza o fraseado mais linear e sem nuances perceptíveis em relação aos ataques consecutivos. De fato, o gráfico revela que a nota Dó no primeiro tempo do c. 62 realizado por este intérprete não é tão prolongada como nas demais execuções. No prosseguimento, nota-se um acelerando em direção ao terceiro tempo do mesmo compasso e um pequeno desacelerando da nota Ré no quarto tempo do c. 62 para a nota Mi no primeiro tempo do c. 63 . Em comparação com a representação gráfica dos demais intérpretes, EM alonga o Mi no primeiro tempo do c. 63 evidenciando uma resolução mais expressiva na nota Dó no segundo tempo do c. 63, final da semifrase.

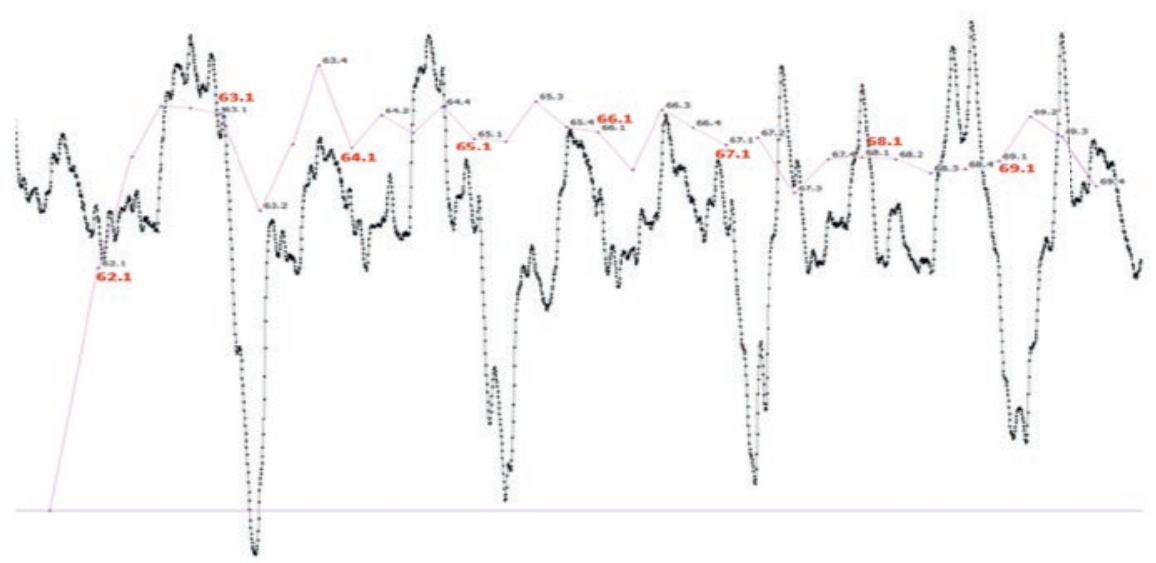

Figura 23: Relação do tempo e da dinâmica na execução de EM (trecho 4, c. 62-69).

\section{Trecho 5 (c. 80-82)}

O trecho 5 é composto pelos dois compassos finais da seção D (c. 80-81) e o c. 82, considerado nesta análise uma quebra de desenho rítmico, ou seja, uma súbita modificação no discurso musical, entre a seção de desenvolvimento e recapitulação, bem como um elemento de ligação entre o final da seção $D$ (c. 58-81) no registro agudo e o início da seção B' (c. 82-100) no registro grave. Os compassos 80-81 são constituídos por uma sequência de tríades diatônicas ascendentes, com várias indicações de tempo, caráter e dinâmica (ppp, rit. e perdendosi, diminuendo, pedal e staccato). $\mathrm{O}$ c. 82, uma sequência de acordes de sétimas diatônicas e descendentes, também exibe uma série de indicações, a saber, animando, affretando, súbito poco rit., articulação não legato, p, crescendo, pedal inteiro e semínima entre 100 a 104, que, por sua vez, resultam em diferentes concepções interpretativas (Figura 24).
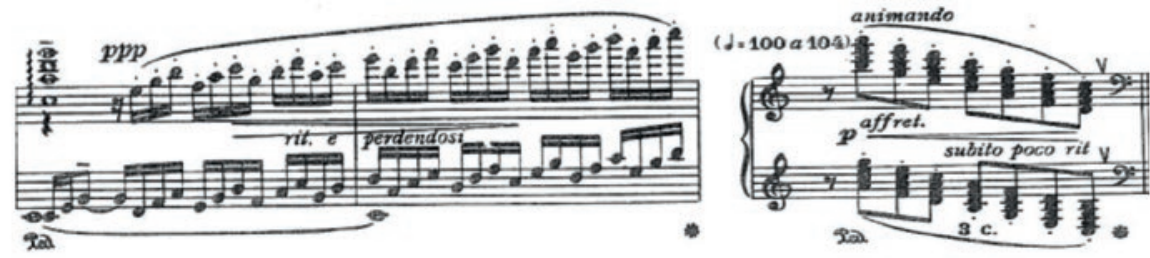

Figura 24: c. 80-82 
O gráfico 7 mostra os desvios de tempo realizados pelos intérpretes nos c. 8082. Observa-se similaridade na construção fraseológica desse trecho e um padrão de aceleração e desaceleração nas execuções, tal como indicado na partitura. As inflexões de timing das gravações analisadas apresentam curvas semelhantes em diversos pontos, no entanto a execução do desacelerando ou do affretando confere singularidade a cada uma das performances. Como será visto no gráfico, algumas realizações são mais enfáticas e enérgicas do que outras.

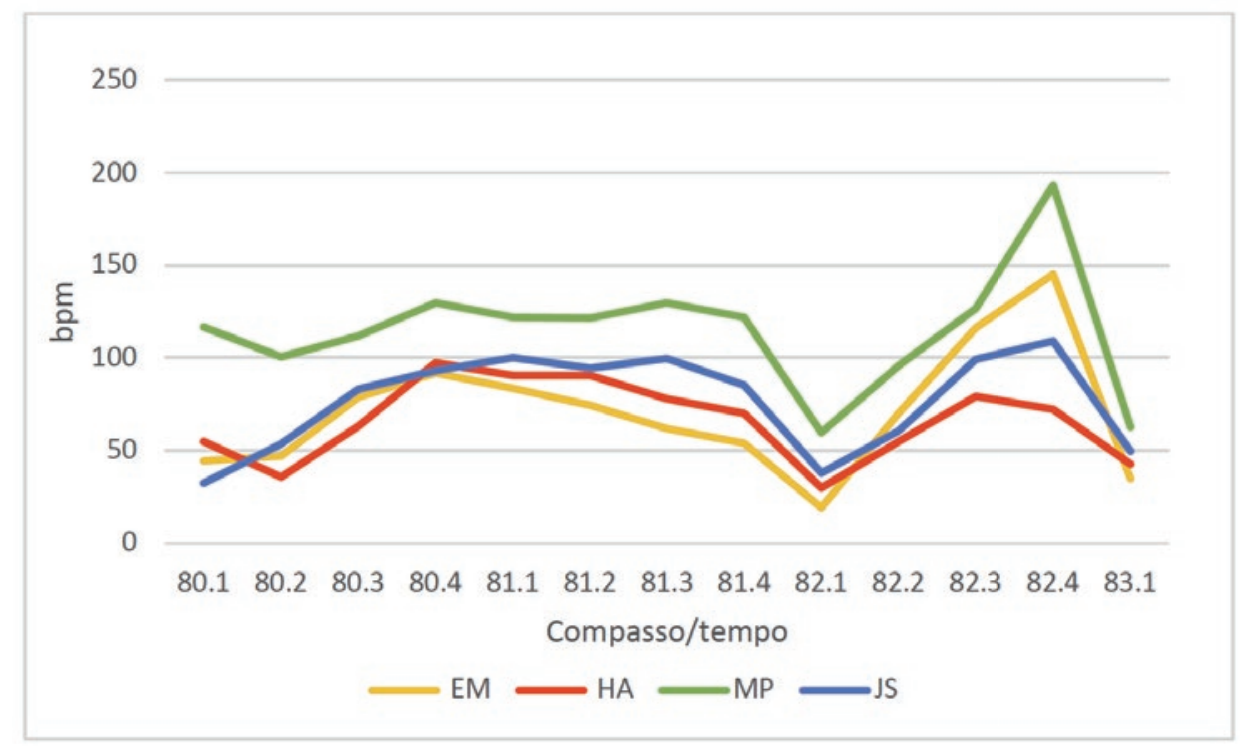

Gráfico 7: Inflexões do timing no trecho 5 (c. 80-82).

Nas execuções desta amostra, observa-se que os intérpretes realizam uma separação agógica na passagem entre os c. 81-82. Nota-se uma diminuição similar do andamento do terceiro tempo do c. 81 para o primeiro tempo do c. 82 , seguido pela aceleração considerável no restante do compasso.

Auditivamente percebe-se maior coerência e correlação temporal e dinâmica na execução de EM, especialmente em relação à indicação de corte do pedal no final do c. 81 e à interrupção de som para realização da pausa de colcheia no primeiro tempo do c. 82. Por outro lado, mesmo tendo uma visualização gráfica semelhante com a linha do tempo de EM, HA não realiza o corte do pedal no final do c. 81 para executar a pausa de colcheia do c. 82. Este pianista escolhe unir as duas ideias sem interromper significativamente o discurso como indicado na partitura.

Nas gravações de MP e JS, ambos realizam com clareza a pedalização do c. 81 e a pausa de colcheia no c. 82, no entanto diferem em dois aspectos na comparação com os demais intérpretes. MP não realiza o ritardando na sequência de tríades do c. $81 \mathrm{e}$ JS não faz a articulação que o compositor indica no c. 82. Ao contrário, JS executa os acordes descendente com articulação curta e sem pedalização e esta escolha contribui para diferenciá-lo dos demais participantes desta amostra.

Na figura 25, constata-se a correlação do tempo e da dinâmica no trecho 5 nas quatro execuções do Primeiro Movimento da Sonata. 
a)

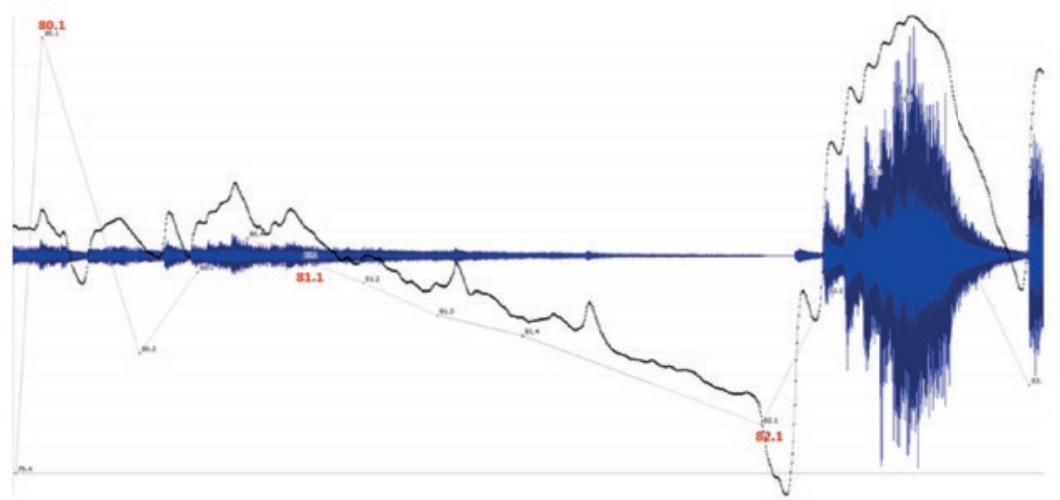

b)

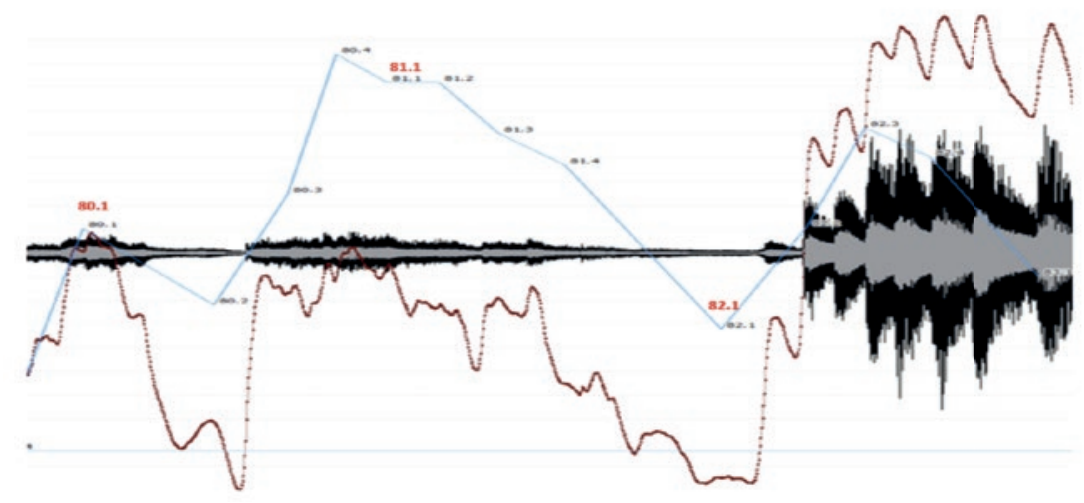

c)

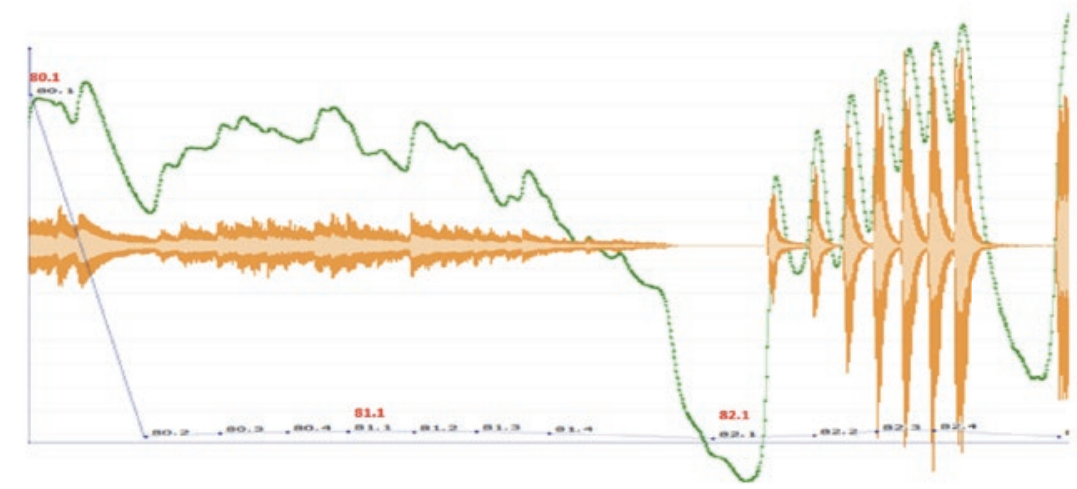

d)

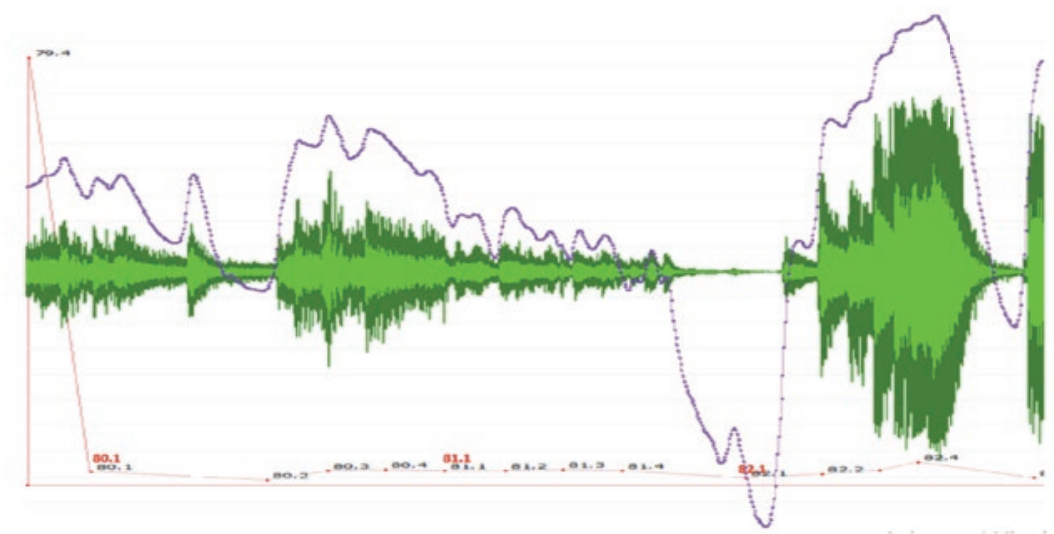

Figura 25: Relação do tempo e da dinâmica nas execuções dos intérpretes: (a) EM; (b) HA; (c) JS; (d) MP - a linha pontilhada indica a curva de dinâmica, a linha reta indica a curva do tempo, forma de onda e em vermelho a numeração dos compassos. 
Particularmente, observa-se na representação gráfica de EM (Figura 25a) a acuidade do intérprete na preparação do ralentando e do decrescendo no c. 81 , seguido pelo afretando e crescendo da dinâmica no c. 82. Auditivamente percebe-se o ralentando no c. 81, no entanto o súbito poco rit. é mais enfático na gravação de HA. Por outro lado, MP não realiza o súbito poco rit., pelo contrário, continua afretando até o final do compasso 82. Na representação gráfica de JS (Figura 25c), é visível a separação dos acordes descendentes em articulação curta no c. 82, contrária à articulação notada e, auditivamente percebe-se que o intérprete realiza o affretando até o final do compasso, tal como MP. De modo geral, assim como nos demais trechos selecionados nesta amostra, os intérpretes partilham de ideias semelhantes em alguns momentos, mas também divergem em outros quanto à manipulação dos recursos expressivos no delineamento do discurso musical da obra.

\section{Considerações finais}

A proposta deste trabalho partiu da ideia de que a abordagem analítica de execuções musicais contribui com informações relevantes sobre aspectos expressivos visto transcender as anotações contidas na partitura. Os dados numéricos obtidos pelo Sonic Visualiser foram graficamente representados e, a partir dos gráficos foram elaborados comentários sobre particularidades de cada gravação em trechos predeterminados. Com essa experiência pude refletir as minhas próprias decisões interpretativas nos trechos em que os pianistas apresentaram diferentes interpretações.

Os aspectos relacionados à sonoridade e principalmente ao tempo relacionam-se, sobretudo, com os padrões recorrentes que caracterizam a Sonata. As inflexões de timing demostraram ser um recurso interpretativo essencial para evidenciar e projetar determinados trechos da obra. As variações de dinâmicas nas execuções forneceram o embasamento necessário no estabelecimento de nuances de sonoridade e expressividade, seja em um compasso, uma frase ou uma seção como, por exemplo, a mudança de sonoridade do mais pesado para o mais leve e, caráter do mais enérgico para o mais ingênuo na seção $D$ (c. 58-81).

As diferenças interpretativas destacadas nesta análise atestam que não há uma única maneira, muito menos uma maneira correta de executar uma obra, mas revela uma gama de possibilidades que podem ser exploradas por cada intérprete para demonstrar seu entendimento do texto musical.

A comparação de gravações com o auxílio de ferramentas computacionais amplificou minha audição e ampliou o meu leque de escolhas como intérprete no sentido de detectar e compreender sutis diferenças de leitura da partitura que resultaram nas interpretações individualizadas da obra. Graças aos recursos computacionais, os elementos musicais analisados nesta amostra foram quantificados e, consequentemente semelhanças e diferenças foram criteriosamente observados.

O meu processo de estudo transcorreu em paralelo às análises e, sendo assim minhas ideias interpretativas foram constantemente testadas e refletidas de acordo com as descobertas no meu processo de audição e comparação das gravações. As ferramen- 
tas computacionais auxiliaram positivamente na observação de detalhes que, muitas vezes, o ouvido não detecta. Por outro lado, os módulos de extensão contidos no Sonic Visualiser convida o ouvinte a valorizar as sutilezas tanto na manipulação do tempo, da dinâmica e também da articulação e do envelope sonoro.

Conclui-se que este tipo de escuta por assim dizer micro e macroscópica foi primordial para compreensão do discurso musical e para expansão dos recursos interpretativos, incluindo-se nesta contribuição as questões de flexibilidade e ampliação da imaginação sonora e da busca pela minha própria forma de expressar as ideias musicais.

\section{Referências}

BENETTI, A. Expressividade e performance pianística. 2013. 315f. Tese (Doutorado em Música) - Universidade de Aveiro, Portugal, 2013.

BRESIN, R.; FRIBERG, A. Emotional coloring of computer controlled music performance. Computer Music Journal, p. 44-62, 2000. Disponível em: <http://www. speech.kth.se/prod/publications/files/724.pdf>. Acesso em 15/10/2017.

CLARKE, E. Processos cognitivos na performance musical. Cipem, Porto, n. 1, p. 61-77, 1999.

Understanding the psychology of performance. In: RINK, J. Musical

performance: a guide to understanding. Cambridge: Cambridge University Press, 2002. p. 59-72.

COGAN, R.; ESCOT, P. Sonic Design: The nature of sound and music. New Jersey: Englewood Cliffs, 1976.

COOK, N; CLARKE, E. Introduction: What is Empirical Musicology. In: CLARKE, E.; COOK, N. (ed). Empirical Musicology: Aims, Methods, Prospects. New York: Oford University Press, 2004. cap. 1, p. 3-14.

GABRIELSSON, A. The performance of Music, In: DEUTSCH, Diana. The Psychology of Music. 2a. Edição. New York: Academic Press, p. 501-602, 1997.

GEIRLAUGSDÓTTIR, S. H. Francisco Mignone e as Sonatas para piano n. 1 e n.4 pela ótica da modernidade. 1997. 138 f. Dissertação (Mestrado em Música) - Universidade Federal do Rio de Janeiro, 1997.

GERLING, F. V. Performance analysis and analysis for performance: a study os VillaLobos's Bachianas Brasileiras n. 9. 2000. 261 f. Ensaio (Doutorado em Artes Musicais) - University of lowa, 2000. 
O tempo rubato na Valsa de Esquina no.2 de Francisco Mignone. Claves. Universidade Federal da Paraíba, n.5, p. 7-19, 2008.

JUSLIN, P. N. Emotion in music Perfomance. In: HALLAM, S; CROSS, I; THAUT, M (Org). Oxford handbook of music psychology. Oxford: Oxford University Press, 2009, p. 377389.

LEECH-WILKINSON, D. The Changing Sound of Music: Approaches to Studying Recorded Musical Performances. (London, CHARM, 2009). Disponível em: <http:// www.charm.rhul.ac.uk/studies/chapters/chap1.html>. Acesso em: 24/02/2018.

MARTINS, J. E. A Pianística Multifacetada de Francisco Mignone. Revista Música, São Paulo, p. 89-113, 1990.

MATSHCULAT, J. Gestos musicais no Ponteio n. 49 de Camargo Guarnieri: análise e comparação de gravações. 2011, 99f. Dissertação (Mestrado), Universidade Federal do Rio Grande do Sul, Porto Alegre, 2011.

\section{Uma comparação entre as duas gravações do Cravo Bem-}

Temperado de J.S. Bach por András Schiff. 2015. 117f. Tese (Doutorado em Música), Universidade Federal do Rio Grande do Sul, Porto Alegre, 2015.

MIGNONE, F. Sonata n.1 para piano. Ricordi Brasileira, São Paulo, 1941. 1 partitura. Piano solo.

PALMER, C. Music Performance. Annual Review of Psychology. The Ohio State University, Columbus, p. 115-134, 1997.

PENEL, A.; DRAKE, C. Timing variations in music performance: musical communication, perceptual compensation, and/or motor control? Perception \& Psychophysics, v.4, n. 66, p. 545-562, 2004. Disponível em: <https://link.springer.com/content/pdf/10.3758/ BF03194900.pdf>. Acesso em: 15/12/2017.

REPP, B. H. Patterns of expressive timing in performances of a Beethoven minuet by nineteen famous pianists. Journal of the Acoustical Society of America, p. 622-641, 1990. Disponível em: < http://asa.scitation.org/doi/abs/10.1121/1.399766>. Acesso em: 13/09/2016.

Diversity and Commonality in Music Performance: An Analysis of Timing Microstructure in Schumann's "Träumerei"'. Journal of the Acoustical Society of America, 1992a, p. 2546-2568. Disponível em: <https://www.researchgate.net/ publication/21676839_Diversity_and_commonality_in_music_performance_An_ analysis_of_timing_microstructure_in_Schumann_Traumerei> Acesso em: 13/09/2016. 
Acoustics, perception, and production of legato articulation on a computer-controlled grand piano. Journal of Acoustical Society of America, p. 18781890, 1997. Disponível em: <http://www.haskins.yale.edu/sr/sr117/SR117_13.pdf>. Acesso em 13/09/2016.

SANTOS, R. T. A.; GERLING, C. C.; BORTOLI, A. L. Modelagem matemática: ferramenta potencial para avaliação das inflexões rítmicas na realização musical de estudantes. Revista da ABEM, Londrina, vol.20, n.27, p.149-162, 2012.

SLOBODA, J. A. Music Performance, In: DEUTSCH, Diana. The Psychology of Music. New York: Academic Press, 1982, p. 479-496.

SHAFFER, L.H. How to Interpret Music. In: JONES, M.R.; HOLLERAN, S. Cognitive Bases of Musical Communication. Washington, DC: American Psychological Association, 1992, p. 263-278.

STOLL, R. E. Variationen für Klavier, op. 27 de Anton Webern: sobre duas práticas de performance distintas a paritr da edição, dos texntos e da gravação de Peter Stadlen e das gravações de Yvonne Loriod e Charles Rosen. 2016, 108f. Dissertação (Mestrado) -Universidade Federal do Rio Grande do Sul, Porto Alegre.

TODD, N.P. McAngus. A Computational Model of Rubato. Contemporary Music Review, 1989, p. 69-88. The dynamics of dynamics: a model of musical expression.

Journal of the Acoustical Society of America, p. 3540-3550, 1992.

The Kinematics of Musical Expression. Journal of the Acoustical Society of America, p. 1940-1949, 1995. Disponível em: <http://asa. scitation.org/doi/abs/10.1121/1.412067>. Acesso em: 07/08/2016.

VERHAALEN, M. The solo piano Music of Francisco Mignone and Camargo Guarnieri. 1971. $271 \mathrm{f}$. Tese (Doctor of Education) - Teachers College, Columbia University, New York, USA, 1971. 